NBER WORKING PAPER SERIES

\title{
INVESTOR SENTIMENT AND \\ THE CROSS-SECTION OF STOCK RETURNS
}

\author{
Malcolm Baker \\ Jeffrey Wurgler \\ Working Paper 10449 \\ http://www.nber.org/papers/w10449 \\ NATIONAL BUREAU OF ECONOMIC RESEARCH \\ 1050 Massachusetts Avenue \\ Cambridge, MA 02138 \\ April 2004
}

We thank Ned Elton, Xavier Gabaix, Owen Lamont, Martin Lettau, Anthony Lynch, Sheridan Titman, and Jeremy Stein for helpful comments, as well as participants of seminars at Baruch College, Chicago Quantitative Alliance, the Federal Reserve Bank of New York, Harvard University, Indiana University, NBER, Norwegian School of Economics and Business, Norwegian School of Management, University of Amsterdam, University of British Columbia, University of Illinois, University of Texas, and University of Wisconsin. We gratefully acknowledge financial support from the Q Group (Baker and Wurgler) and the Division of Research of the Harvard Business School (Baker). The views expressed herein are those of the author(s) and not necessarily those of the National Bureau of Economic Research.

C2004 by Malcolm Baker and Jeffrey Wurgler. All rights reserved. Short sections of text, not to exceed two paragraphs, may be quoted without explicit permission provided that full credit, including (C) notice, is given to the source. 
Investor Sentiment and the Cross-Section of Stock Returns

Malcolm Baker and Jeffrey Wurgler

NBER Working Paper No. 10449

April 2004

JEL No. G12

\section{ABSTRACT}

We examine how investor sentiment affects the cross-section of stock returns. Theory predicts that a broad wave of sentiment will disproportionately affect stocks whose valuations are highly subjective and are difficult to arbitrage. We test this prediction by studying how the cross-section of subsequent stock returns varies with proxies for beginning-of-period investor sentiment. When sentiment is low, subsequent returns are relatively high on smaller stocks, high volatility stocks, unprofitable stocks, non-dividend-paying stocks, extreme-growth stocks, and distressed stocks, consistent with an initial underpricing of these stocks. When sentiment is high, on the other hand, these patterns attenuate or fully reverse. The results are consistent with predictions and appear unlikely to reflect an alternative explanation based on compensation for systematic risk.

Malcolm Baker

Harvard Business School

Morgan Hall 361

Boston, MA 02163

and NBER

mbaker@hbs.edu

Jeffrey Wurgler

Stern School of Business, Suite 9-190

New York University

44 West 4th Street

New York, NY 10012

and NBER

jwurgler@stern.nyu.edu 


\section{Introduction}

Classical finance theory gives no role to investor sentiment. Investors are rational and diversify to optimize the statistical properties of their portfolios. Competition among them leads to an equilibrium in which prices equal the rationally discounted value of expected cash flows, and in which the cross-section of expected returns depends on the cross-section of systematic risks. ${ }^{1}$ Even if some investors are irrational, classical theory argues, their demands will be offset by arbitrageurs and similar conclusions for prices will obtain.

In this paper, we present evidence that investor sentiment actually has strong effects on the cross-section of stock prices. We start with simple theoretical predictions. Given that a mispricing is the result of an uninformed demand shock in the presence of a binding arbitrage constraint, a broad-based wave of sentiment is predicted to have cross-sectional effects, as opposed to raise or lower all prices equally, when either sentiment-based demands very across stocks or arbitrage constraints vary across stocks. In practice, these two channels lead to quite similar predictions, because stocks that are likely to be most sensitive to speculative demand those with highly subjective valuations - also tend to be the riskiest and costliest to arbitrage. Concretely, then, theory suggests two separate channels through which the stocks of newer, smaller, highly volatile firms, firms in distress or with extreme growth potential, firms without dividends, and firms with like characteristics, would be expected to be relatively more affected by investor sentiment.

To investigate this prediction empirically, and to get a more tangible sense of the intrinsically elusive concept of investor sentiment, we begin with a brief summary of rises and falls in U.S. market sentiment from 1961 through the recent Internet bubble. This summary is

\footnotetext{
${ }^{1}$ See Gomes, Kogan, and Zhang (2003) for a recent model in this tradition.
} 
based on anecdotal accounts and thus is only suggestive, but it appears broadly consistent with our theoretical predictions, and suggests more formal empirical tests are warranted.

Our main empirical approach is as follows. Because cross-sectional patterns of sentimentdriven mispricing would be difficult to identify directly, we look for the hypothesized patterns in subsequent stock returns that appear when one conditions on proxies for beginning-of-period investor sentiment. The idea is that conditional cross-sectional patterns in subsequent returns may represent the initial patterns of mispricing correcting themselves over time. For example, relatively low future returns on young firms when sentiment was measured to be high suggests that young firms were overvalued ex ante. As usual, there is a joint hypothesis problem with this approach. We must also consider the possibility that any such predictability patterns are compensation for systematic risks.

The first step is to gather proxies for investor sentiment to use as time series conditioning variables. We use a number of proxies suggested by recent work, and we also construct a novel composite index based on their first principal component. To further reduce the likelihood that these proxies are connected to systematic risks, we orthogonalize each of them to a wide range of macroeconomic conditions. The resulting sentiment proxies are highly correlated and visibly line up with anecdotal accounts of past bubbles.

We then examine whether the cross-section of stock returns varies with beginning-ofperiod sentiment in the predicted manner. We use monthly stock returns between 1963 and 2001. Our first method is to sort firm-month observations according to the level of sentiment, first, and then the decile rank of a given firm characteristic, second. We find that when sentiment is low (below sample median), small stocks earn particularly high subsequent returns, but when sentiment is high (above median), there is no size effect at all. Conditional patterns are even 
sharper when sorting on other characteristics. When sentiment is low subsequent returns are higher on young stocks than older stocks, high-return volatility than low-return volatility stocks, unprofitable stocks than profitable ones, and nonpayers than dividend payers. When sentiment is high, these patterns completely reverse. In other words, several characteristics that were not known to have (and do not have) any unconditional predictive power actually reveal sign-flip patterns, in the predicted directions, when one conditions on sentiment.

The sorts also suggest that sentiment affects extreme growth and distressed firms in similar ways. When stocks are sorted into deciles by sales growth, book-to-market, or external financing activity, growth and distress firms tend to lie at opposing extremes, with more stable firms in middle deciles. We find that when sentiment is low, the subsequent returns on stocks at both extremes are especially high relative to their unconditional average, while stocks in middle deciles are less affected by sentiment. This U-shaped pattern in the conditional difference of subsequent returns also appears consistent with theoretical predictions, because both extremegrowth and distressed firms are likely to have relatively subjective valuations and to be relatively hard to arbitrage. Again, note that this pattern, like the monotonic conditional patterns described above, are averaged away in unconditional studies.

We confirm the statistical significance of these patterns with two regression approaches, and then turn to the alternative explanation that they reflect compensation for systematic risks. As a start, our sentiment proxies are orthogonal to contemporaneous macroeconomic conditions. In addition, other aspects of the results cast doubt on this explanation. Note that it requires either time variation in rational, market-wide risk premia or time variation in the cross-sectional pattern of risk, i.e., beta loadings. We test the second possibility directly and find no link between the patterns in predictability and patterns in betas with market returns or consumption growth. If risk 
is not changing over time, then the first possibility requires not just time-variation in risk premia but changes in sign - meaning that in half of our sample period (when sentiment proxies are low), old, less volatile, profitable, dividend-paying firms require a risk premium over young, highly volatile, unprofitable, nonpayers. Such a pattern is at best counterintuitive. Finally, we uncover some conditional patterns in returns around firms' earnings announcements, which suggest that a component of the results can be attributed to expectational errors. For these reasons, compensation for systematic risk is not a promising explanation.

The evidence presented here challenges the classical view of the cross-section of stock prices and carries significant implications, some of which we mention in the conclusion. Here we note that the paper builds on several current themes in asset pricing. The results complement earlier work that suggests that sentiment helps to explain the time series of returns (Kothari and Shanken (1997), Neal and Wheatley (1998), Shiller (1981, 2000), and Baker and Wurgler (2000)). Recent work including Campbell and Cochrane (2000), Wachter (2000), Lettau and Ludvigson (2001), and Menzly, Santos, and Veronesi (2002) examines the effects of conditional systematic risks; we condition on sentiment. Daniel and Titman (1997) test a characteristicsbased model for the cross-section of expected returns; we extend their specification and provide it with a specific, conditional motivation. Shleifer (2000) surveys early work on sentiment and limited arbitrage, two key theoretical ingredients here. Barberis and Shleifer (2003), Barberis, Shleifer, and Wurgler (2003), and Peng and Xiong (2002) discuss models of category-level trading, and Fama and French (1993) document strong comovement of stocks of similar sizes and book-to-market ratios; sentiment-driven demand shocks for categories of stocks with similar characteristics are central to our results. Finally, we unify and extend previously-documented 
relationships among sentiment, IPOs, and small stock returns (Lee, Shleifer, and Thaler (1991), Swaminathan (1996), and Neal and Wheatley (1998)).

Section II derives predictions. Section III provides a qualitative history of recent speculative episodes. Section IV describes the empirical hypotheses and the data, and the main empirical tests are contained in Section V. Section VI concludes.

\section{Theoretical effects of sentiment on the cross-section}

A mispricing is the result of an uninformed demand shock and a limit on arbitrage. This observation suggests that there are two distinct channels through which investor sentiment, as defined more precisely below, might affect the cross-section of stock prices. In the first channel, sentimental demand shocks vary in the cross-section, while limits on arbitrage are held constant. In the second, the difficulty of arbitrage varies across stocks but sentiment is generic. We discuss the two channels in turn.

\section{A. Cross-sectional variation in sentiment}

One possible definition of investor sentiment is the propensity to speculate. Under this definition, sentiment drives the relative demand for speculative investments, and so causes crosssectional effects even if arbitrage forces are the same across stocks.

What makes certain stocks more vulnerable to broad shifts in the propensity to speculate? Perhaps the main factor is the subjectivity of their valuations. For instance, consider a canonical young, unprofitable, extreme-growth potential stock. The lack of an earnings history combined with the presence of apparently unlimited growth opportunities allows unsophisticated investors to defend, with equal plausibility, a wide spectrum of valuations, from much too low to much too high, as suits their sentiment. In a bubble period, when the propensity to speculate is apparently 
high, this profile of characteristics also allows investment bankers or, worse, swindlers, to further argue for the high end of valuations. By contrast, the value of a firm with a long earnings history and stable dividends is much less subjective, and so its stock is likely to be less affected by fluctuations in the propensity to speculate. ${ }^{2}$

This channel suggests how variation in the propensity to speculate may generally affect the cross-section, but not how sentimental investors actually choose stocks. We suggest that they simply demand stocks that have the bundle of salient characteristics that is compatible with their sentiment. ${ }^{3}$ That is, those with a low propensity to speculate may demand profitable, dividendpaying stocks not because profitability and dividends are correlated with some unobservable firm property that defines safety, but precisely because the salient characteristics "profitability" and "dividends" are used to infer safety. ${ }^{4}$ Likewise, the salient characteristics "no earnings," "young age," and "no dividends" may mark the stock as speculative. This investment process seems potentially more realistic than that of Markowitz (1959), in which investors view individual securities in terms of their statistical properties.

\section{B. Cross-sectional variation in arbitrage}

\footnotetext{
${ }^{2}$ The favorite-longshot bias in racetrack betting is a nice application of the idea that investors with a high propensity to speculate (racetrack bettors) will overprice the most speculative bets (longshots have the most negative expected returns; see Hausch and Ziemba (1995)).

${ }^{3}$ The idea that investors view securities as a vector of salient characteristics borrows from Lancaster (1966, 1971), who views consumer demand theory from the perspective that the utility of a consumer good (e.g, oranges) derives from more primitive characteristics (fiber and vitamin $\mathrm{C}$ ).

${ }^{4}$ The implications of categorization for finance have recently been explored by Baker and Wurgler (2003), Barberis and Shleifer (2003), Barberis, Shleifer, and Wurgler (2003), Greenwood and Sosner (2003), and Peng and Xiong (2002). Note that if investors infer category membership from salient characteristics (some psychologists propose that category membership is determined by the presence of defining or characteristic features, e.g. Smith, Shoben, and Rips (1974)), then sentiment-driven demand will be directly connected to characteristics even if sentimental investors undertake an intervening process of categorization and trade entirely at the category level. It is also empirically convenient to boil key investment categories down into vectors of stable and measurable characteristics: one can use the same empirical framework to study such episodes as the late-1960's growth stocks bubble and the Internet bubble.
} 
Investor sentiment might also be reasonably defined as optimism or pessimism about stocks in general. Indiscriminate waves of sentiment still affect the cross-section, however, if arbitrage forces are relatively weaker in a subset of stocks.

This channel is better understood than the cross-sectional variation in sentiment channel. A body of theoretical and empirical research shows that arbitrage tends to be particularly risky and costly for young, small, unprofitable extreme-growth or distressed stocks. Their high idiosyncratic risk makes relative-value arbitrage especially risky (Wurgler and Zhuravskaya (2002)). They tend to be more costly to trade (Amihud and Mendelsohn (1986)) and particularly expensive, sometimes impossible, to sell short (D’Avolio (2002), Geczy, Musto, and Reed (2002), Jones and Lamont (2002), Duffie, Garleanu, and Pedersen (2003), Lamont and Thaler (2003), and Mitchell, Pulvino, and Stafford (2002)). Further, their lower liquidity also exposes would-be arbitrageurs to predatory attacks (Brunnermeier and Pedersen (2003)).

Note that, in practice, it is generally the case that the same stocks that are the hardest to arbitrage are also most vulnerable to sentiment. While for expositional purposes we outline these two channels separately, they are likely to have overlapping effects. And while this makes the channels themselves difficult to distinguish empirically, it makes it easier to derive robust empirical predictions for the cross-sectional effects of sentiment, broadly defined. Indeed, the two channels may even amplify each other. For example, the fact that investors can convince themselves of an especially wide range of valuations in certain regions of the cross-section is a noise-trader risk that further deters short-horizon arbitrageurs (De Long, Shleifer, Summers, and Waldmann (1990) and Shleifer and Vishny (1997)). ${ }^{5}$

\footnotetext{
${ }^{5}$ We do not incorporate the equilibrium prediction of DeLong et al., namely that securities with more exposure to sentiment have higher unconditional expected returns. Elton, Gruber, and Busse (1998) argue that expected returns are not higher on stocks that have higher sensitivities to the closed-end fund discount, a proxy for investor sentiment.
} 


\section{An anecdotal history of investor sentiment, 1961-2002}

In this section we offer a brief summary of U.S. stock market bubbles between 1961 to 2002, matching the period of our own data. The reader eager to see results may skip this section, but it will prove useful for three reasons. First, despite great interest in the effects of investor sentiment, the literature does not appear to contain even the most basic qualitative description of recent speculative episodes. Second, a knowledge of the rough timing of these episodes will allow us to make a preliminary judgment about the accuracy of the quantitative proxies for sentiment we develop later. Third, the discussion sheds some initial, albeit anecdotal light on the plausibility of our theoretical predictions.

Our brief history of sentiment is distilled from several secondary sources. Kindleberger (2001) draws general lessons from bubbles and crashes over the past few hundred years, while Brown (1991), Dreman (1979), Graham (1973), Malkiel (1990, 1999), Shiller (2000), and Siegel (1998) focus more specifically on recent U.S. stock market episodes. We take each of these accounts with a grain of salt, and emphasize only those themes that appear repeatedly.

We start in 1961, a year in which Graham (1973), Malkiel (1990) and Brown (1991) note a high demand for small, young, growth stocks. Dreman (1979, p. 70) confirms their accounts. Malkiel writes of a "new-issue mania" that was concentrated on new "tronics" firms. "... The tronics boom came back to earth in 1962. The tailspin started early in the year and exploded in a horrendous selling wave ... Growth stocks took the brunt of the decline, falling much further than the general market" (p. 54 - 57).

The next bubble develops in 1967 and 1968. Brown writes that "scores of franchisers, computer firms, and mobile home manufactures seemed to promise overnight wealth. ... [while] 
quality was pretty much forgotten" (p. 90). Malkiel and Dreman also note this pattern - a focus on firms with strong earnings growth or potential, and an avoidance of "the major industrial giants, 'buggywhip companies,' as they were sometimes contemptuously called”' (Dreman 1979, p. 74-75). Another characteristic apparently out of favor was dividends. According to the New York Times, “during the speculative market of the late 1960's many brokers told customers that it didn't matter whether a company paid a dividend - just so long as its stock kept going up" (9/13/1976). But "after 1968, as it became clear that capital losses were possible, investors came to value dividends" (10/7/1999). In summarizing the performance of stocks from the end of 1968 through August 1971, Graham (1973) writes: “[our] comparative results undoubtedly reflect the tendency of smaller issues of inferior quality to be relatively overvalued in bull markets, and not only to suffer more serious declines than the stronger issues in the ensuing price collapse, but also to delay their full recovery - in many cases indefinitely" (p. 212).

Anecdotal accounts invariably describe the early 1970's as a bear market, with sentiment at a low level. However, a set of established, large, stable, consistently profitable stocks known as the "nifty fifty" enjoyed notably high valuations. Brown, Malkiel, and Siegel (1998) each highlight this episode. Siegel writes, "All of these stocks had proven growth records, continual increases in dividends ... and high market capitalization" (p. 106). Note that this speculative episode is a mirror image of those described above (and below). They center on small, young, unprofitable growth stocks in periods of high sentiment, while the nifty fifty episode appears to be a bubble in a set of firms with an opposite set of characteristics (old, large, and continuous earnings and dividend growth) and happens in a period of low sentiment.

The late 1970's through mid-1980's are described as a period of generally high sentiment that saw a series of speculative episodes. Dreman describes a bubble in gambling issues in 1977 
and 78. Ritter (1984) studies the hot issue market of 1980, finding greater initial returns on IPOs of natural resource start-ups than on larger, mature, profitable offerings. Of 1983, Malkiel (p. 7475) writes that "the high-technology new-issue boom of the first half of 1983 was an almost perfect replica of the 1960's episodes ... The bubble appears to have burst early in the second half of 1983 ... the carnage in the small company and new-issue markets was truly catastrophic." Brown confirms this account. Of the mid-1980's, Malkiel writes that "What electronics was to the 1960's, biotechnology became to the 1980's. ... new issues of biotech companies were eagerly gobbled up. ... having positive sales and earnings was actually considered a drawback" (p. 77-79). But by 1987 and 1988, "market sentiment had changed from an acceptance of an exciting story ... to a desire to stay closer to earth with low-multiple stocks that actually pay dividends" (p. 79).

The late-1990's bubble in technology stocks will be familiar to the reader. By all accounts, sentiment was broadly high before the bubble began to burst in 2000. Cochrane (2002) and Ofek and Richardson (2002) offer detailed perspectives on the bubble. Malkiel draws parallels to episodes in the 1960's, 1970's, and 1980's, and Shiller (2000) compares the Internet bubble to the late 1920's. As in earlier speculative episodes that occurred in high sentiment periods, demand for dividend payers seems to have been low (New York Times, 1/6/1998). Ljungqvist and Wilhelm (2003) find that $80 \%$ of 1999 and 2000 IPOs had negative earnings per share and that the median age of 1999 IPOs was 4 years. This contrasts with an average age of over 9 years just prior to the emergence of the bubble, and of over 12 years by 2001 and 2002 (Ritter, 2003).

These anecdotal accounts suggest that there may indeed be regular patterns in the effect of sentiment on the cross-section. One pattern seems to be that canonical extreme-growth stocks 
are especially prone to bubbles, and subsequent crashes, consistent with the observation that they are relatively appealing to speculators and optimists and at the same time are hard to arbitrage. The "nifty fifty" bubble is an exception to this pattern. However, anecdotal accounts suggest that this bubble occurs in a period of broadly low sentiment, so it might still be consistent with our main cross-sectional prediction that an increase in sentiment will increase the relative price of stocks that are most subjective to value and hardest to arbitrage. We turn to more formal tests of this prediction.

\section{Empirical approach and data}

\section{A. Empirical approach}

Theory and historical anecdote both suggest that sentiment may cause systematic patterns of mispricing. Because mispricing is hard to identify directly, however, we will look for systematic patterns of correction of mispricings in the form of conditional patterns in crosssectional return predictability. For example, a pattern in which returns on young and unprofitable firms are low when beginning-of-period sentiment is estimated to be high may represent the correction of a bubble in growth stocks.

Specifically, we organize our empirical work around the following model:

$$
E_{t-1}\left[R_{i t}\right]=a+\mathbf{b}_{1}{ }^{\prime} \mathbf{x}_{i t-1}+\mathbf{b}_{2}{ }^{\prime} T_{t-1} \mathbf{x}_{i t-1}
$$

where $i$ indexes firms or securities, $t$ is time, $\mathbf{x}$ is a vector of firm or security characteristics, and $T$ is a time series conditioning variable that proxies for investor sentiment. The null hypothesis is that $\mathbf{b}_{2}$ is zero or, more precisely, that any nonzero effect is due to rational compensation for bearing systematic risk. The alternative is that $\mathbf{b}_{2}$ is nonzero and reflects the correction of 
mispricings. We refer to Eq. (1) as a "conditional characteristics model," as it adds conditional effects to the characteristics model of Daniel and Titman (1997).

We use Eq. (1) as an organizing framework to test for conditional characteristics effects, not as a structural model. We will sort stocks by $\mathbf{x}$ and $T$ and tabulate the subsequent returns in each bin, and we will run predictive regressions. Either way, the strategy is to see whether the manner in which characteristics spread future returns depends on the sentiment proxies used as conditioning variables. This will help us to answer the first-order question of whether sentiment, broadly defined, has cross-sectional effects. We will also address the question of whether any conditional characteristics effects reflect mispricing or compensation for systematic risk. We will leave interesting but subtler questions, such as the extent to which rejections of the null are due to cross-sectional variation in sentiment or constraints on arbitrage, to future research.

\section{B. Characteristics and returns}

The firm-level data is from the merged CRSP-Compustat database. The sample includes all common stock (share codes 10 and 11) of nonfinancial firms (excluding SIC code 6) between 1962 through 2001. Following Fama and French (1992), we match accounting data for fiscal year-ends in calendar year $t$ - 1 to (monthly) returns from July $t$ through June $t+1$, and we also tend to use their variable definitions.

Table 1 shows summary statistics. Panel A summarizes returns variables. Following common practice, momentum $M O M$ is defined as the cumulative raw return for the elevenmonth period between 12 and two months prior to the observation return. (Note we will examine momentum as a control or robustness variable, not as a firm characteristic in itself.)

The remaining panels summarize the firm and security characteristics that we consider. The previous sections' discussions point us directly to several variables. To that list, we add a 
few more characteristics that, by introspection, seem likely to be salient to investors. Overall, we group characteristics roughly, as pertaining most directly to firm size and age, profitability, dividends, growth opportunities, and distress.

Panel B summarizes size and age characteristics. Market equity $M E$ from June of year $t$, measured as price times shares outstanding from CRSP, is matched to monthly returns from July of year $t$ through June of year $t+1$. Age is the number of years since the firm's first appearance on CRSP, measured to the nearest month. ${ }^{6}$ Sigma is the standard deviation of monthly returns over the twelve months ending in June of year $t$. If there are at least nine returns to estimate it, Sigma is then matched to monthly returns from July of year $t$ through June of year $t+1$.

Panel $C$ summarizes profitability characteristics. The return on equity $E+/ B E$ is positive for profitable firms and zero for unprofitable firms. Earnings $(E)$ is income before extraordinary items (Item 18) plus income statement deferred taxes (Item 50) minus preferred dividends (Item 19), if earnings are positive; book equity $(B E)$ is shareholders equity (Item 60) plus balance sheet deferred taxes (Item 35). $E>0$ is a dummy variable for profitable firms.

Panel D summarizes dividend characteristics. Dividends to equity $D / B E$ is dividends per share at the ex date (Item 26) times Compustat shares outstanding (Item 25) divided by book equity. $D>0$ is a dummy for positive dividends per share by the ex date. The recent decline in the percentage of firms that pay dividends noted by Fama and French (2001) is apparent. As they point out, this is partly attributable to the increasing proportion of unprofitable firms.

Panel E summarizes characteristics that serve as indictors of growth opportunities, distress, or both. The elements of book-to-market equity $B E / M E$ are defined above. External finance activity $E F / A$ is defined as the change in assets (Item 6) minus the change in retained

\footnotetext{
${ }^{6}$ Barry and Brown (1984) use the more accurate term "period of listing." A large number of firms appear on CRSP for the first time in December 1972, when coverage of NASDAQ begins. Excluding these firms from our analyses of age does not change any of our inferences.
} 
earnings (Item 36) divided by assets. Sales growth $(G S)$ is the change in net sales (Item 12)

divided by prior-year net sales. We measure and report sales growth $G S / 10$ as the decile of the firm's sales growth in the prior year relative to NYSE firms' decile breakpoints.

It is important to bear in mind that the variables in Panel E capture multiple effects. For instance, book-to-market wears three distinct hats: extremely high values are likely to indicate distress; extremely low values are likely to indicate high growth opportunities; and, as a scaledprice variable, book-to-market also serves as a generic valuation indicator, varying with any source of mispricing or rational expected returns. The sales growth and external finance variables wear at least two hats: extremely low values (which are negative) are likely to indicate distress; extremely high values are likely to indicate high growth opportunities. Also, to the extent that market timing motives are important to external finance, that variable also serves as a generic misvaluation indicator.

In Panels C, D, and E, the accounting data for fiscal years ending in calendar year $t$ - 1 are matched to monthly returns from July of year $t$ through June of year $t+1$. To reduce the influence of outliers and data errors, all of the explanatory variables are Winsorized each year at their 0.5 and 99.5 percentiles.

\section{Investor sentiment}

Prior work suggests a number of proxies for sentiment to use as time-series conditioning variables. Of course, there is no such thing as a perfect measure of sentiment, and each of the available proxies has disadvantages. But to determine the extent to which our results are robust, we consider six separate proxies - the average closed-end fund discount, NYSE share turnover, the number and average first-day returns on IPOs, the equity share in new issues, and the 
dividend premium - as well as a composite index based on their first principal component. The sentiment proxies are measured annually from 1962 through 2001.

To isolate the sentiment component of the proxies from business cycle components, we orthogonalize each proxy with respect to several macroeconomic variables. Specifically, we regress each of the raw proxies on growth in the industrial production index (Federal Reserve Statistical Release G.17), growth in consumer durables, nondurables, and services (all from BEA National Income Accounts Table 2.10), and a dummy variable for NBER recessions. We take the residuals from these regressions as a cleaner proxy that is independent of major business cycle effects. All of our results are based on these cleaned proxies.

Table 2 summarizes the raw proxies in Panel A and the cleaned versions in Panel B. Figure 1 plots both versions. The closed-end fund discount $C E F D$ is the average difference between the NAV of closed-end stock fund shares and their market prices. Prior work suggests that the discount is inversely related to sentiment. Zweig (1973) uses the discount to forecast reversion in Dow Jones stocks, and Lee, Shleifer, and Thaler (1991) argue that sentiment explains several features of the discount. We take the value-weighted average discount on closed-end stock funds for 1962 through 1993 from Neal and Wheatley (1998), for 1994 through 1998 from CDA/Wiesenberger, and for 1999 through 2001 from turn-of-the-year issues of the

\section{Wall Street Journal.}

NYSE share turnover is based on the ratio of reported share volume to average shares listed from the NYSE Fact Book. Baker and Stein (2002) suggest that turnover, and more generally liquidity, can serve as a sentiment index. In a market with short-sales constraints, irrational investors participate and thus add liquidity only when they are optimistic, and hence high liquidity tends to coincide with overvaluation. Consistent with this interpretation, Jones 
(2001) finds that high turnover forecasts low market returns. Turnover displays an exponential positive trend over our period, however, and the May 1975 elimination of fixed commissions have a visible effect. As a partial solution, the raw turnover ratio TURN is detrended by the fiveyear moving average (specifically, the log of the ratio is detrended by its moving average). This helps the variable to identify sharp changes in turnover, but it will clearly still pick up the sharp changes caused by market structure.

The IPO market is often viewed as sensitive to sentiment, and high first-day returns on IPOs may also be a measure of investor enthusiasm. Likewise, the low idiosyncratic returns on IPOs are often interpreted in terms of market timing (Stigler (1964), Ritter (1991)). We take the number of IPOs NIPO and the average first-day returns $R I P O$ in a given year from Jay Ritter's website, which updates the sample in Ibbotson, Sindelar, and Ritter (1994). Of course, there are many non-sentiment reasons for why IPO volume and so-called underpricing vary over time, but they do not have direct implications for cross-sectional return predictability.

The share of equity issues in total equity and debt issues is another measure of financing activity that may capture an aspect of sentiment. Baker and Wurgler (2000) find that when the equity share is in its bottom (top) historical quartile, the next year's equal-weighted market return averages $27 \%(-8 \%)$, and argue that part of this predictability reflects market timing by firms made possible by sentiment-driven mispricing. The equity share is defined as gross equity issuance divided by gross equity plus gross long-term debt issuance using data from the Federal Reserve Bulletin. $^{7}$

\footnotetext{
${ }^{7}$ While they both reflect equity issues, the number of IPOs and the equity share have important differences. The equity share includes seasoned offerings, is known to predict market returns, and scales by total external finance to isolate the composition of finance from the level. On the other hand, the IPO variables may better reflect demand for certain IPO-like regions of the cross-section that theory and history suggest are most sensitive to sentiment.
} 
The dividend premium $P^{D-N D}$ is the $\log$ difference of the average market-to-book ratios of payers and nonpayers. Baker and Wurgler (2002) motivate the dividend premium as a proxy for relative investor demand for dividend payers. Because Fama and French (2001) find that payers are larger, more profitable, and have weaker growth opportunities, the dividend premium may also pick up the relative investor demand for this correlated bundle of characteristics.

Intuitively, to detect the hypothesized cross-sectional patterns in predictability, we want to condition on turning points in investor sentiment. But the sentiment proxies themselves have certain lead-lag relationships, raising the possibility that different variables may reflect the same sentiment factor at different times. For instance, Ibbotson and Jaffe (1975), Lowry and Schwert (2002), and Benveniste, Wilhelm, Ljungqvist, and Yu (2003) find that IPO volume lags the firstday returns on IPOs. One interpretation of this fact is that sentiment is in part behind the high first-day returns, and this attracts additional IPO volume with a lag. More generally, proxies that involve firm supply responses ( $S$ and $N I P O$ ) are likely to lag proxies that are based on investor demand or investor behavior (RIPO, $P^{D-N D}, T U R N$, and CEFD).

We also form a novel composite index SENTIMENT in order to capture the common factor in the six proxies, and to help us identify their best relative timing. The procedure is as follows. We start by estimating the first principal component of the six proxies and their lags. This gives us a first-stage index with twelve loadings, one for each of the current and lagged proxies. We then compute the correlation between the first-stage index and the current and lagged values of each of the proxies. Finally, we construct SENTIMENT as the first principal component of the correlation matrix of six variables - each proxy's lead or lag, whichever has the higher correlation with the first-stage index.

This procedure leads to a final, more parsimonious index: 


$$
\begin{aligned}
\text { SENTIMENT }_{t}= & -0.358 \text { CEFD }_{t}+0.402 T U R N_{t-1}+0.414 N I P O_{t} \\
& +0.464 \text { IIPO }_{t-1}+0.371 S_{t}-0.431 P_{t-1}^{D-N D}
\end{aligned}
$$

where for Eq. (2) each of the six components was first cleaned of macroeconomic conditions and standardized. The first principal component explains 53\% of the (standardized) sample variance, and only the first eigenvalue is above 1.00 , so we conclude that one factor captures the common variation. The correlation between the twelve-term first-stage index and the SENTIMENT index is 0.96 , suggesting that little information is lost in dropping six terms.

Certain aspects of this index are intuitively appealing. First, each individual sentiment proxy enters with the expected sign. Second, all but one of the proxies enter with the expected timing - with the exception of $C E F D$, price and investor behavior variables lead firm supply variables. We will make use of this pattern in the subsequent analysis, i.e. we will condition on the first predetermined value of $C E F D, N I P O, S$, and SENTIMENT, and the lag of that value for $T U R N, R I P O$, and $P^{D-N D}$. Third, the index irons out some extreme observations. The dividend premium and the first-day IPO returns reached unprecedented levels in 1999, so for these proxies to work as individual predictors in the full sample, these levels must be matched exactly to extreme future returns.

Figure 1 shows that the sentiment proxies line up well with anecdotal accounts of sentiment. Most proxies point to low sentiment in the first few years of the sample, which follow the 1961 crash in growth stocks - the closed-end fund discount and dividend premium are high, while turnover and equity issuance-related variables are low. Each variable identifies a spike in sentiment in 1968 and 1969, again matching anecdotal accounts. Sentiment then tails off until, by the mid-1970's, it is low by most measures (recall that for turnover this is confounded by the deregulation). The late 1970's through mid-1980's sees generally rising sentiment, and according 
to the composite index, sentiment has not dropped below a medium level since 1980. At the end of 1999 , near the peak of the Internet bubble, sentiment is again high by most proxies.

This correspondence with anecdotal accounts is encouraging. It confirms, to the extent possible, that the proxies capture the intended variation. Also notable is that cleaning the proxies of macro conditions has little effect on their time-series properties. Indeed, Table 2 suggests that the cleaned proxies are equally if not more correlated with each other than are the raw proxies, suggesting that investor sentiment can be distinguished from macroeconomic conditions. Again, we consider only the cleaned proxies in our subsequent empirical work, in order to isolate the effect of sentiment from macroeconomic conditions.

\section{Empirical tests}

\section{A. Sorts}

Table 3 looks for conditional characteristics effects in a simple, nonparametric way. We place each monthly return observation into a bin according to the decile rank that a characteristic takes at the beginning of that month, and then according to the level of a sentiment proxy from the end of the previous calendar year. We compute the average monthly return for that bin and look for patterns. We report sorts on CEFD in Table 3a and SENTIMENT in Table 3b. As discussed above, we condition returns from calendar year $t$ on the December of year $t$ - 1 values of CEFD and SENTIMENT. Also, to keep the meaning of the deciles relatively constant over time, we define them based on NYSE firms. The tradeoff is that there is not a uniform distribution of firms across bins in a given month.

For brevity, we omit sorts on the five other sentiment proxies. They give similar results, available upon request, and they are broken out separately in all subsequent tables because they 
fit more compactly. But it is worth showing results for the index component $C E F D$ alongside the overall index, however, because $C E F D$ is perhaps our cleanest "general" indicator of investor sentiment - it is not mechanically connected to sentiment for any one segment of the crosssection. In contrast, the volume of IPOs and the dividend premium could in principle be driven by a concentrated demand for firms with IPO characteristics or dividends, respectively. By comparing the results for $C E F D$ to the results for other sentiment proxies, or the composite index, we can more clearly document a general sentiment effect.

The first rows of Table 3 show the effect of size conditional on sentiment. They reveal that the cross-sectional size effect of Banz (1981) exists in low-sentiment conditions only, i.e. when CEFD is positive or SENTIMENT is negative (a final reminder that here, and in all subsequent tables, the sentiment proxies are net of macroeconomic effects). Specifically, Table $3 \mathrm{~b}$ shows that when SENTIMENT is negative, returns average 2.33 percent per month for the bottom $M E$ decile and 0.91 for the top decile. A similar pattern is apparent when conditioning on CEFD; a link between the size effect and closed-end fund discounts was previously noted by Swaminathan (1996). This pattern helps make sense of some long-known results. Namely, the size effect was known to be largely a January effect (Keim (1983), Blume and Stambaugh (1983)), and the January effect, in turn, was known to be stronger after a period of low returns (Reinganum (1983)), which is when sentiment is likely to be low.

As an aside, note that the average returns across the first two rows of Table 3 show that subsequent returns tend to be higher across the board when sentiment is low. This is consistent with prior results that the equity share and turnover, for example, forecast market returns. More generally, it supports our premise that sentiment has broad effects, and so the existence of richer patterns within the cross-section should not be entirely surprising. 
The conditional cross-sectional effect of Age is especially striking. It seems that investors tend to demand young stocks when SENTIMENT is positive and old stocks when sentiment is negative. This is suggested by the conditional difference in returns between decile 10 and decile 1 stocks. When SENTIMENT is pessimistic, top-decile Age firms return 0.47 percent less than bottom-decile Age firms, but return 0.72 percent more when SENTIMENT is optimistic. This is intriguing because Age shows no unconditional effect at all. ${ }^{8}$ The strong conditional effects simply average out across high and low sentiment periods.

The next rows indicate that the cross-sectional effect of return volatility is conditional on sentiment in the hypothesized manner. In particular, high Sigma stocks appear to be out of favor when SENTIMENT is low - they earn returns of 2.25 percent per month. However, just as with Age, the cross-sectional effect of Sigma fully reverses in low sentiment conditions.

The next rows examine profitability and dividends. For investors, perhaps the simplest and most salient comparison is between profitable and unprofitable $(E<0)$ firms and payers and nonpayers $(D=0)$. These contrasts are summarized in the extreme right columns, where we average returns across profitable firms and compare them to unprofitable firms, and do the same for dividends. These characteristics again display conditional sign-flip patterns. Table $3 \mathrm{~b}$ shows that when SENTIMENT is positive, monthly returns are 0.32 percent higher on profitable than unprofitable firms and 0.45 percent higher on payers than nonpayers. When it is negative, however, returns are 0.85 percent per month lower on profitable firms and 0.77 percent lower on payers. Importantly, the left column shows that these patterns are driven mostly by conditional variation in the returns of unprofitable and nonpaying firms. As discussed above, because these

\footnotetext{
${ }^{8}$ This conclusion is in seeming contrast to Barry and Brown (1984)'s evidence of an unconditional negative periodof-listing effect, but their sample excludes stocks listed for fewer than 61months.
} 
firms tend to be more subjective to value and harder to arbitrage, theory predicts that they will be more sensitive to swings in sentiment.

The remaining variables - book-to-market, external finance, and sales growth - also display intriguing patterns. Most simply, running across rows, one can see that each of them has some unconditional explanatory power. Expected returns are generally higher for high $B E / M E$ stocks, low EF/A stocks, and low $G S$ decile stocks. The $E F / A$ result is reminiscent of Loughran and Ritter (1995) and Spiess and Affleck-Graves (1995, 1999), while the GS result is suggested in Lakonishok, Shleifer, and Vishny (1994).

A closer look also reveals a conditional pattern in these variables. Specifically, each sort displays a U-shaped pattern in the conditional difference in average returns. Consider the $G S$ variable in Table $3 \mathrm{~b}$. When SENTIMENT is high, there is (roughly speaking) an inverted Ushaped pattern across $G S$ deciles, which is summarized in the 5-1 and 10-5 decile contrasts. When sentiment changes sign, however, this flips to become (roughly speaking) an upward U. As a result, the difference across sentiment regimes is a pronounced inverted $U$.

Similar U-shaped patterns appear in the conditional differences across $E F / A$ and $B E / M E$ deciles. But one must be somewhat careful in interpreting these patterns. As noted above, $E F / A$ and $B E / M E$ may identify extreme growth opportunities and distress but also may serve as generic valuation indicators. Thus viewed in isolation, the conditional patterns in these variables could be taken as reflecting the conditional demand for categories of stocks other than extreme growth and distressed stocks. On the other hand, casual intuition, as well as the fact that the EF/A and $B E / M E$ patterns match the pattern that appears in the conceptually straightforward $G S$ variable, suggests that at least a large portion of the $E F / A$ and $B E / M E$ patterns can be attributed to the conditional pricing of growth and distress. 
Overall, the U-shaped conditional difference pattern suggests that investors demand both high growth and distressed firms when they are optimistic, or their speculative propensity is high, and avoid these extremes when they are pessimistic, or their propensity to speculate is low. That sentiment has special implications for distressed firms is not emphasized in anecdotal histories of market bubbles and crashes, but is consistent with theoretical predictions, because both rapidly-growing firms and those teetering on the brink are difficult to value and, among other deterrents to arbitrage, have high idiosyncratic risk. Such stocks are therefore predicted to be more sensitive to sentiment than the "stable" firms in the middle deciles of sorts on $G S, E F / A$, and $B E / M E$.

\section{B. Predictive regressions for individual stocks}

We turn to cross-sectional predictive regressions. We run monthly cross-sectional predictive regressions and then study how the coefficients change with investor sentiment. Compared to the sorts, this approach allows us to conduct formal inference, to determine which characteristics have conditional predictive ability that is distinct from well-known unconditional effects, and to present results for each of our sentiment proxies in a compact fashion.

As a baseline, we estimate the unconditional predictive ability of each characteristic. Each month, we run a cross-sectional univariate predictive regression:

$$
R_{i t}=a+b_{t} X_{i t-1}+\varepsilon_{i t}
$$

where $X$ is a given characteristic. For earnings and dividends characteristics, we simply consider the profitability and payer dummies, because the sorts suggest that these capture the main effects. ${ }^{9}$

\footnotetext{
${ }^{9}$ In a similar spirit, Gruber (1966) documents changes in the cross-sectional determinants of stock prices between 1951 and 1963. He proposes that they are connected to changes in investor time horizon, i.e., shifts in the term structure of discount rates.
} 
Figure 2 reports the time series of the coefficients from these rolling regressions, and Panel A of Table 4 reports the average monthly coefficient and t-statistics based on the standard deviation of the coefficients, as in Fama and MacBeth (1973). They confirm prior results that size, book-to-market, external finance, and sales growth have unconditional predictive power.

Panel B runs multivariate cross-sectional regressions to distinguish novel unconditional effects from the well-known effects of size, book-to-market, and momentum:

$$
R_{i t}=a+b_{t} X_{i t-1}+s_{t} \log (M E)_{i t-1}+h_{t} \log (B E / M E)_{i t-1}+m_{t} M O M_{i t-1}+\varepsilon_{i t}
$$

where $X$ denotes the characteristic of interest. (There is no $X$ when we consider size and book-tomarket themselves.) Age is modestly significant, sales growth loses some of its unconditional effect, and external finance retains a strong independent effect.

The key question is whether and how these coefficients change with investor sentiment. Are the fluctuations in Figure 2 connected to, or anticipated by, those in Figure 1? In Table 5, we address this question by regressing the monthly regression coefficients on sentiment proxies. The first several columns regress coefficients obtained from (3) on each of the proxies, while the last column regresses coefficients obtained from (4) on the composite index: ${ }^{10}$

$$
\hat{b}_{t}=c+d \operatorname{SENTIMENT} T_{t-1}+\varepsilon_{t}
$$

The sentiment proxies are all standardized. Standard errors are bootstrapped to correct for the bias induced if the autocorrelated sentiment proxies have innovations that are correlated with innovations in the coefficients, as in Stambaugh (1999).

The results basically confirm the sorts. As sentiment increases (lower $C E F D_{t-1}$ or $P^{D-N D}{ }_{t-2}$ or higher $T_{U R N} N_{t-2}, N I P O_{t-1}, R I P O_{t-2}, S_{t-1}$, or SENTIMENT $T_{t-1}$ ), expected returns tend to decrease on small firms, young firms, firms with volatile returns, unprofitable firms, and non-dividend-

\footnotetext{
${ }^{10}$ Intuitively, in terms of Eq. (1), this procedure is regressing estimates of $\left(\mathrm{b}_{1}+\mathrm{b}_{2} T_{t-1}\right)$ on sentiment proxies $T_{t-1}$.
} 
paying firms. In all cases the results are in the expected direction, and those using IPO volume as the sentiment proxy are particularly strong. While these effects clearly overlap to some extent, the last column shows that the connection between the cross-sectional effect of these variables and SENTIMENT can often be distinguished from arbitrarily time-varying effects of size, bookto-market, and momentum.

We give an example to illustrate the magnitude of the effects. In the second-to-last columns of Table 5, the 0.1 coefficient of SENTIMENT on ME means that a two-SD increase in the sentiment index raises the size coefficient by 0.2 percentage points per month. Table 4 shows that such a change would bring the conditional size effect from negative to zero, and this is in turn consistent with the Table $3 \mathrm{~b}$ result that there is no size effect in high sentiment periods.

Like the sorts, the regressions show that the cross-sectional effects of book-to-market, external finance, and sales growth do not have a strong monotonic relationship with sentiment. To capture their U-shaped conditional effects, we re-run (3) and (4) for these characteristics but limit the regression sample to observations that fall within the top or bottom seven deciles of these variables. ${ }^{11}$ The idea is to look at one side of the $\mathrm{U}$ at a time. For instance, the $G S(1-7)$ row examines how the cross-sectional effect of sales growth varies with sentiment among firms in the lower range of sales growth, where a marginal increase predominantly reflects a move away from distress, not a move toward extreme growth. The GS (4-10) row examines the crosssectional effect of sales growth in a range where the main effect of a marginal increase is an move toward extreme growth, not a move away from distress. Effectively, we view $G S(1-7)$ and GS (4-10) as separate characteristics with different meanings.

\footnotetext{
${ }^{11}$ The decision of how many deciles to cut out is obviously somewhat arbitrary. The choice of three follows Fama and French (1993), who identify the top three $B E / M E$ deciles with value and the bottom three with growth.
} 
Figure 2 plots the cross-sectional coefficients from these regressions. The plots show clearly that these characteristics have different cross-sectional effects in the bottom and top of their ranges. The last several rows of Table 5 indicate that this method successfully captures the U-shaped conditional effects in book-to-market, external finance, and sales growth. As we found in the sorts, future returns on stocks with characteristics of either extreme growth or distress are negatively related to sentiment proxies. Some calculations will confirm that the size of the effects implied here are similar to those suggested in the sorts.

\section{Predictive regressions for long-short portfolios}

A third way to look for conditional characteristics effects is to use sentiment to forecast portfolios that are long on stocks with high values of a characteristic and short on stocks with low values. We have just seen that the average payer, for example, earns higher returns than the average nonpayer when sentiment is high, so sentiment must forecast a long-short portfolio formed on dividend payment. But it is useful to examine explicitly whether sentiment affects portfolios like $S M B$ and $H M L$, for example, because they are often used to proxy for systematic risks. In addition, the portfolio method is less parametric than the regressions for individual stocks. To the extent that it delivers similar results, then, it indicates that the results are not driven by changes in the cross-sectional distribution of firm characteristics.

The first several columns of Table 6 use individual sentiment proxies to predict longshort portfolios: ${ }^{12}$

$$
R_{X_{i t}=H i g h, t}-R_{X_{i t}=\text { Low }, t}=c+d \operatorname{SENTIMENT} T_{t-1}+\varepsilon_{i t} .
$$

The dependent variable is the monthly return on a long-short portfolio, such as $S M B$, and the monthly returns from January through December of $t$ are regressed on the lagged sentiment

\footnotetext{
${ }^{12}$ In terms of Eq. (1), this regresses $\left(\mathrm{b}_{1} \Delta X+\mathrm{b}_{2} T_{t-1} \Delta X\right)$ on sentiment proxies $T_{t-1}$, where $\Delta X$ is the difference between "high" and "low" levels of a characteristic.
} 
proxies. The last column again attempts to separates novel comovement effects from well-known effects using a multivariate prediction:

$$
\begin{aligned}
& R_{X_{i t}=H i g h, t}-R_{X_{i t}=\text { Low }, t}=c+d \text { SENTIMENT } \\
& +-1+\beta R M K T_{t}+s S M B_{t} \\
& +h H M L_{t}+m U M D_{t}+\varepsilon_{i t}
\end{aligned}
$$

Obviously, we must exclude $S M B$ and $H M L$ from the right side when those are the portfolios being forecast. $R M R F$ is the excess return of the value-weighted market over the risk-free rate. $U M D$ is the return on high-momentum stocks, where momentum is measured over the period from 12 months prior through 2 months prior, minus the return on low-momentum stocks. As described in Fama and French (1993), $S M B$ is the return on portfolios of small and big $M E$ stocks that is separate from returns on $H M L$, and $H M L$ is constructed to isolate the difference between high- and low- $B E / M E$ portfolios. ${ }^{13}$

For profitability and dividend payment, the coefficients estimated from the portfolio approach are identical to those estimated from the individual stock approach by construction. The other results are similar (the sign for predicting $S M B$ is expected to be the opposite of the earlier $M E$ sign). $S M B$ is significantly related to sentiment in some specifications, while there is again an U-shaped conditional effect in $H M L$ and especially in the long-short portfolios formed on external finance and sales growth. We separate extreme growth opportunities effects from distress effects by constructing High, Medium, and Low portfolios based on the top three, middle four, and bottom three NYSE decile breakpoints, respectively. Using sentiment to forecast the High-Medium portfolio for sales growth, for example, is then analogous to using it to predict the cross-sectional effect of $G S$ (4-10).

\section{Systematic risk}

\footnotetext{
${ }^{13}$ These portfolios are taken from Ken French's website and are described there.
} 
At face value, the conditional characteristics effects seem unlikely to be compensation for systematic risk. Among other considerations, the sentiment proxies have been orthogonalized to macroeconomic conditions; the patterns match theoretical predictions about where the effects of sentiment should be most pronounced; and the patterns line up with anecdotal accounts of bubbles and crashes. Intuitively, the systematic risk explanation requires that older, profitable, dividend-paying firms are (when sentiment is high, i.e. in half of the sample) actually require higher returns than younger, unprofitable, nonpaying firms, and are recognized as such by the marginal investor. While this seems counterintuitive, we can consider, and largely rule out, this alternative explanation more rigorously.

Systematic risk explanations come in two basic flavors. One is that the systematic risks (beta loadings) of stocks with certain characteristics vary with the sentiment proxies, despite our effort to isolate them from macro conditions. Table 7 investigates this directly. It asks whether sentiment coincides with time-variation in market betas in a way that could at least qualitatively reconcile the earlier results with a conditional CAPM. Specifically, we predict returns on the characteristics portfolios:

$$
R_{X_{i t}=H i g h, t}-R_{X_{i t}=L o w, t}=c+d S E N T I M E N T_{t-1}+\beta\left(e+f S E N T I M E N T_{t-1}\right) R M R F_{t}+\varepsilon_{i t} .
$$

The time-varying betas story predicts that the composite coefficient $\beta f$, reported in Table 7 , is of the same sign as the estimates of $d$ in Table 6. However, it turns out that when the coefficient $\beta f$ is statistically significant, it is the wrong sign in a majority of cases. We find similar results when we replace $R M R F$ by aggregate consumption growth. A table is available upon request.

The second systematic risk story keeps stocks' betas fixed, but allows the risk premium to vary with sentiment, which means that the difference in required returns between the high- and low-beta stocks varies in proportion. However, this story runs into trouble with the simple fact 
that the predicted effect of several characteristics does not just vary in magnitude over time, but in direction. This discussion, and the results of the next exercise, leads us to conclude that the results do not reflect compensation for classical systematic risks.

\section{E. $\quad$ Predictive regressions for earnings announcement returns}

Our last test is whether there are conditional characteristics effects in the returns around earnings announcements. La Porta, Lakonishok, Shleifer, and Vishny (1997) find that low bookto-market stocks have lower average returns at earnings announcements than high book-tomarket stocks, suggesting systematic errors in earnings expectations. Likewise, if errors in earnings expectations account for some of our results, we might expect that the average earnings announcement return on small, young, volatile, unprofitable, nonpaying, extreme growth and/or distress stocks would tend to be inversely related to sentiment.

This methodology, while appealing, has only limited power to detect how expectational errors affect our results. The essence of our results appears to be the correlated correction of mispricing, but a firm's announcement event return picks up the expectational corrections that occur only to it alone and within its own announcement window. Malkiel (1999) illustrates the problem: "The music slowed drastically for the conglomerates on January 19, 1968. On that day, the granddaddy of the conglomerates, Litton Industries, announced that earnings for the second quarter of that year would be substantially less than forecast. ... the announcement was greeted with disbelief and shock. In the selling wave that followed, conglomerate stocks declined by roughly 40 percent ..." (p. 67). So, while a study of announcement event returns will capture the corrective effect of Litton Industries' announcement on its own stock, it will pick up none of its broader effects, which are important to our main results. Nevertheless, an analysis of earnings 
announcements may provide a lower bound on the effect that sentiment-driven expectational errors have on our results.

We gather quarterly earnings announcement dates from the merged CRSP-Compustat file. These dates are available beginning in January 1971. The quarterly earnings announcement sample represents approximately $75 \%$ of the firm-quarters (firm-months) analyzed in the main tables, so coverage is fairly complete. For each firm-quarter observation, we compute the cumulative abnormal return over the value-weighted market index over trading days $[-1,+1]$ around the report date. We then construct a quarterly series of average announcement effects for each characteristic decile, and attempt to predict it with the composite sentiment index:

$$
C A R_{X_{i t}=\text { Decile, }}=c+d S E N T I M E N T_{t-1}+\varepsilon_{i t}
$$

Table 8 reports the coefficient estimates for each characteristic decile.

The patterns in Table 8 need to be compared to those in Table 3b. In Table 8,12 of the 82 coefficients are significant at the 5\% level. In Table 3b, on the other hand, 10 of the 82 estimated effects are very large in the sense that sentiment is associated with an conditional difference in monthly returns of over 1.50 percentage points. The intersection of these tables" "strong results" is six cells, and the signs agree in all cases. In addition, four of the five cells that are strong in Table $3 \mathrm{~b}$ but not significant in Table 8 have matching signs; in the opposite direction, five of the six significant results in Table 8 that are not associated with very large effects in Table $3 \mathrm{~b}$ are at least of the same sign. One anomaly is the significantly negative coefficient on the oldest firms, but perhaps at least one anomaly is to be expected by chance in so many implicit comparisons.

Overall, this exercise suggests that some portion of the conditional characteristics effects probably reflects the correction of conditional errors in earnings expectations. But as noted 
above, this test is not very powerful, and thus provides only a lower bound on the contribution of expectational errors.

\section{Conclusion}

In classical finance theory, "investor sentiment" plays no role on the cross-section of stock prices, returns, or expected returns. This paper takes issue with the classical view. It marshals theoretical considerations, historical accounts of speculative episodes, and most importantly a set of novel empirical findings, in support of the view that investor sentiment, broadly defined, has significant cross-sectional effects.

To summarize, the main empirical finding is that the cross-section of future stock returns is conditional upon beginning-of-period proxies for investor sentiment. The patterns are rich, but straightforward to interpret and consistent with simple theoretical predictions. Specifically, when sentiment appears to be high, stocks that are likely to be relatively attractive to optimists and speculators and at the same time unattractive candidates for arbitrage - young stocks, small stocks, unprofitable stocks, non-dividend paying stocks, high-volatility stocks, extreme-growth stocks, and distressed stocks - experience low future returns relative to other stocks. Conditional on low sentiment, on the other hand, these cross-sectional patterns attenuate or reverse. Several aspects of the results cast doubt on the hypothesis that they reflect rational compensation for systematic risk. Rather, they match simple theoretical predictions and line up well with historical accounts of bubbles and crashes.

The conclusion that sentiment has broad cross-sectional effects obviously carries with it a number of significant implications for financial economics. Here we highlight one application of our results, involving dividend policy. An old question is whether dividend payers endure higher 
costs of equity when there is a gap between income and capital gains rates, as in Brennan (1970), or whether dividends are irrelevant. Black and Scholes (1974), Miller and Scholes (1982), and Christie and Huang (1984), among others, find that the cross-sectional effect of the dividend yield on (pre-tax) returns is not reliably positive and actually quite unstable over time. This is often interpreted as rejecting the tax hypothesis in favor of the classical irrelevance view. Our results, however, suggest that both views may be incorrect. While the cross-sectional effect of dividends is indeed unstable, its sign is predictable by sentiment. So viewed as a whole, the facts seem better explained by the idea dividends are relevant to current valuations but with a timevarying sign that depends on relative investor demand for payers and nonpayers, as in the catering theory of dividends of Baker and Wurgler (2002).

The results suggest several avenues for future work. In corporate finance, a better understanding of sentiment may shed light on time-series patterns in security issuance and the supply of firm characteristics that seem to be conditionally relevant to share price. For asset pricing, the results indicate that descriptively accurate models of expected returns need to better incorporate investor sentiment. The best way to do this is unclear; the conditional characteristics specification studied here offers a starting point. More generally, we have said little about how and why investor sentiment forms, arguing only that it is a very real force with effects in the cross-section of stock prices. An open question is whether there are necessary macroeconomic preconditions for investor sentiment to bloom. 


\section{References}

Amihud, Yakov, and Haim Mendelson, 1986, Asset pricing and the bid-ask spread, Journal of Financial Economics, 17, 223-49.

Baker, Malcolm, and Jeremy Stein, 2002, Market liquidity as a sentiment indicator, NBER Working Paper Series, No. 8816.

Baker, Malcolm, and Jeffrey Wurgler, 2000, The equity share in new issues and aggregate stock returns, Journal of Finance 55, 2219-57.

Baker, Malcolm, and Jeffrey Wurgler, 2002, A catering theory of dividends, Journal of Finance, forthcoming.

Banz, Rolf, 1981, The relationship between return and market value of common stocks, Journal of Financial Economics 9, 3-18.

Barberis, Nicholas, and Andrei Shleifer, 2003, Style investing, Journal of Financial Economics 68, 161-199.

Barberis, Nicholas, Andrei Shleifer, and Jeffrey Wurgler, 2003, Comovement, Journal of Financial Economics, forthcoming.

Barry, Christopher B., and Stephen J. Brown, 1984, Differential information and the small firm effect, Journal of Financial Economics 13, 283-294.

Benveniste, Lawrence M., Alexander P. Ljungqvist, William J. Wilhelm, Jr., and Xiaoyun Yu, 2003, Evidence of information spillovers in the production of investment banking services, Journal of Finance 58, 577-608.

Black, Fischer, and Myron S. Scholes, 1974, The effects of dividend yield and dividend policy on common stock prices and returns, Journal of Financial Economics 1, 1-22.

Blume, Marshall, and Robert Stambaugh, 1983, Biases in computed returns: An application to the size effect, Journal of Financial Economics 12, 387-404.

Brennan, Michael J., 1970, Taxes, market valuation and corporate financial policy, National Tax Journal 23, 417-427.

Brown, John Dennis, 1991, 101 Years on Wall Street, Prentice Hall.

Brunnermeier, Markus, and Lasse Pedersen, 2003, Predatory trading, Princeton working paper.

Campbell, John Y., and John H. Cochrane, 2000, Explaining the poor performance of consumption-based asset pricing models, Journal of Finance 55, 2863-2878.

Christie, William, and Roger Huang, 1994, The changing functional relation between stock returns and dividend yields, Journal of Empirical Finance 1, 161-191.

Cochrane, John H., 2002, Stocks as money: Convenience yield and the tech-stock bubble, NBER Working Paper Series, No. 8987.

D'Avolio, Gene, 2002, The market for borrowing stock, Journal of Financial Economics 66, 271-306.

Daniel, Kent, and Sheridan Titman, 1997, Evidence on the characteristics of cross-sectional variation in stock returns, Journal of Finance 46, 1739-1764.

De Long, J. Bradford, Andrei Shleifer, Lawrence H. Summers, and Robert Waldmann, 1990, Noise trader risk in financial markets, Journal of Political Economy 98, 703-738.

Dreman, David, 1979, Contrarian Investment Strategy, Dreman Contrarian Group.

Duffie, Darrell, Nicolae Garleanu, and Lasse H. Pedersen, 2002, Securities lending, shorting, and pricing, Journal of Financial Economics 66, 307-339.

Elton, Edwin J., Martin J. Gruber, and Jeffrey A. Busse, 1998, Do investors care about sentiment?, Journal of Business 71, 477-500. 
Fama, Eugene F., and James MacBeth, 1973, Risk, return, and equilibrium: Empirical tests, Journal of Political Economy 81, 607-636.

Fama, Eugene F., and Kenneth R. French, 1992, The cross-section of expected stock returns, Journal of Finance 47, 427-465.

Fama, Eugene F., and Kenneth R. French, 1993, Common risk factors in the returns on stocks and bonds, Journal of Financial Economics 33, 3-56.

Fama, Eugene F., and Kenneth R. French, 2001, Disappearing dividends: Changing firm characteristics or lower propensity to pay?, Journal of Financial Economics 60, 3-44.

Geczy, Christopher C., David K. Musto, and Adam V. Reed, 2002, Stocks are special too: An analysis of the equity lending market, Journal of Financial Economics 66, 241-269.

Gomes, Joao, Leonid Kogan, and Lu Zhang, 2003, Equilibrium cross section of returns, Journal of Political Economy 111, 693-732.

Graham, Benjamin, 1973, The Intelligent Investor, $4^{\text {th }}$ ed., Harper \& Row.

Greenwood, Robin, and Nathan Sosner, 2002, Trade and the comovement of stock returns: Evidence from Japan, Harvard University working paper.

Gruber, Martin J., 1966, The Determinants of Common Stock Prices, Ph.D. dissertation, Columbia University.

Hausch, Donald, and William Ziemba, 1995, Efficiency of sports and lottery betting markets, In: Handbooks in Operations Research and Management Science, vol. 9, Elsevier.

Ibbotson, Roger, and Jeffrey F. Jaffe, 1975, 'Hot issue' markets, Journal of Finance 30, 1027-42.

Ibbotson, Roger, Jody Sindelar, and Jay Ritter, 1994, The market's problems with the pricing of initial public offerings, Journal of Applied Corporate Finance 7, 66-74.

Jones, Charles, 2001, A century of stock market liquidity and trading costs, Columbia University working paper.

Jones, Charles, and Owen Lamont, 2002, Short sale constraints and stock returns, Journal of Financial Economics 66, 207-239.

Keim, Donald, 1983, Size-related anomalies and stock return seasonality: Further empirical evidence, Journal of Financial Economics 12, 13-32.

Kothari, S.P., and Jay Shanken, 1997, Book-to-market, dividend yield, and expected market returns: A time-series analysis, Journal of Financial Economics 44, 169-203.

Kindleberger, Charles, 2001, Manias, Panics, and Crashes, Wiley.

La Porta, Rafael, Josef Lakonishok, Andrei Shleifer, and Robert W. Vishny, 1997, Good news for value stocks: Further evidence on market efficiency, Journal of Finance 52, 859-74.

Lakonishok, Josef, Andrei Shleifer, and Robert W. Vishny, 1994, Contrarian investment, extrapolation, and risk, Journal of Finance 49, 1541-1578.

Lamont, Owen A., and Richard H. Thaler, 2003, Can the market add and subtract? Mispricing and tech stock carve-outs, Journal of Political Economy 111, 227-268.

Lee, Charles, Andrei Shleifer, and Richard H. Thaler, Investor sentiment and the closed-end fund puzzle, Journal of Finance 46, 75-109.

Lettau, Martin, and Sydney Ludvigson, 2001, Resurrecting the (C)CAPM: A cross-sectional test when risk premia are time-varying, Journal of Political Economy 109, 1238-87.

Ljunqvist, Alexander and William Wilhelm, 2003, IPO pricing in the dot-com bubble, Journal of Finance 58, 723-752.

Loughran, Tim and Jay Ritter, 1995, The new issues puzzle, Journal of Finance 50, 23-51.

Lowry, Michelle and G. William Schwert, 2002, IPO market cycles: Bubbles or sequential learning?, Journal of Finance 57, 1171 - 1200. 
Malkiel, Burton, 1990, A Random Walk Down Wall Street, W.W. Norton.

Malkiel, Burton, 1999, A Random Walk Down Wall Street, W.W. Norton.

Markowitz, Harry, 1959, Portfolio Selection: Efficient Diversification of Investments, John Wiley, New York.

Menzly, Lior, Tano Santos, and Pietro Veronesi, 2002, The time series of the cross section of asset prices, University of Chicago working paper.

Miller, Merton H., and Myron S. Scholes, 1982, Dividends and taxes: Some empirical evidence, Journal of Political Economy 90, 1118-1141.

Mitchell, Mark L., Pulvino, Todd, and Erik Stafford, 2002, Limited arbitrage and equity markets, Journal of Finance 57, 551-584.

Neal, Robert, with Simon Wheatley, 1998, Do measures of investor sentiment predict stock returns, Journal of Financial and Quantitative Analysis 34, 523-547.

Ofek, Eli and Matthew Richardson, 2002, DotCom Mania: The rise and fall of internet stocks, Journal of Finance 58, 1113-1138.

Peng, Lin, and Wei Xiong, 2002, Capacity constrained learning and asset price comovement, Princeton University working paper.

Reinganum, Marc R., 1983, The anomalous stock market behavior of small firms in January: Empirical tests for tax-loss selling effects, Journal of Financial Economics 12, 89-104.

Ritter, Jay, 1984, The 'hot issue' market of 1980, The Journal of Business 57, 215-40.

Ritter, Jay, 1991, The long-run performance of initial public offerings, Journal of Finance 46, 327.

Ritter, Jay, 2003, Some factoids about the 2002 IPO market, University of Florida working paper.

Shiller, Robert J., 1981, Do stock prices move too much to be justified by subsequent changes in Dividends?, American Economic Review 71, 421-436.

Shiller, Robert J., 2000, Irrational Exuberance, Princeton University Press.

Shleifer, Andrei, 2000, Inefficient Markets, Oxford University press.

Shleifer, Andrei, and Robert W. Vishny, 1997, The limits of arbitrage, Journal of Finance 52, 35-55.

Siegel, Jeremy, 1998, Stocks for the Long Run, McGraw-Hill.

Smith, E. E., E. J., Shoben, and L. J. Rips, 1974, Structure and process in semantic memory: A featural model for semantic decisions, Psychological Review 81, 214-241.

Speiss, D. Katherine, and John Affleck-Graves, 1995, Underperformance in long-run stock returns following seasoned equity offerings, Journal of Financial Economics 38, 243267.

Spiess, Katherine, and John Affleck-Graves, 1999, The long-run performance of stock returns following debt offerings, Journal of Financial Economics 54, 45-73.

Stambaugh, Robert F., 1999, Predictive regressions, Journal of Financial Economics 54, 375421.

Stigler, George J., 1964, Public regulation of the securities markets, Journal of Business 37, 117142.

Swaminathan, Bhaskaran, 1996, Time-varying expected small firm returns and closed-end fund discounts, Review of Financial Studies 9, 845-87.

Wachter, Jessica, 2000, Habit formation and the cross-section of asset returns, Ch. 4 of Ph.D. dissertation, Harvard University. 
Wurgler, Jeffrey, and Katia Zhuravskaya, 2002, Does arbitrage flatten demand curves for stocks?, Journal of Business 75, 583-608.

Zweig, Martin E., 1973, An investor expectations stock price predictive model using closed-end fund premiums, Journal of Finance 28, 67-87. 
Figure 1. Investor Sentiment. The first panel shows the year-end, value-weighted average discount on closed-end mutual funds. The data on prices and net asset values (NAVs) come from Neal and Wheatley (1998) for 1962 through 1993; CDA/Wiesenberger for 1994 through 1998; and turn-of-the-year issues of the Wall Street Journal for 1999 and 2000. The second panel shows detrended log turnover. Turnover is the ratio of reported share volume to average shares listed from the NYSE Fact Book. We detrend using the past five-year average. The third panel shows the annual number of initial public offerings. The fourth panel shows the average annual first-day returns of initial public offerings. Both series come from Jay Ritter, updating data analyzed in Ibbotson, Sindelar, and Ritter (1994). The fifth panel shows gross annual equity issuance divided by gross annual equity plus debt issuance from Baker and Wurgler (2000). The sixth panel shows the year-end log ratio of the value-weighted average market-to-book ratios of payers and nonpayers from Baker and Wurgler (2003). The dashed line (left axis) is raw data. We regress each measure on the growth in industrial production, the growth in durable, nondurable and services consumption, the growth in employment and a flag for NBER recessions. The solid line (right axis) is the residuals from this regression. The final panel presents a first principal component index of the six orthogonalized measures. In the index, turnover, the average annual first-day return, and the dividend premium are lagged one year relative to the other three measures.

Panel A. Closed-end fund discount \%

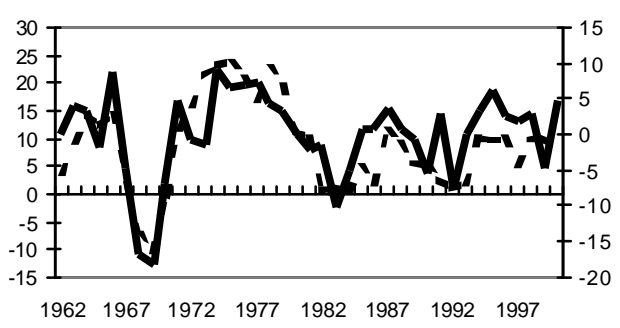

Panel C. Number of IPOs

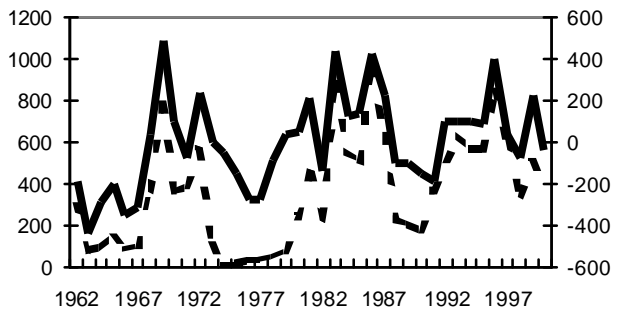

Panel E. Equity share in new issues

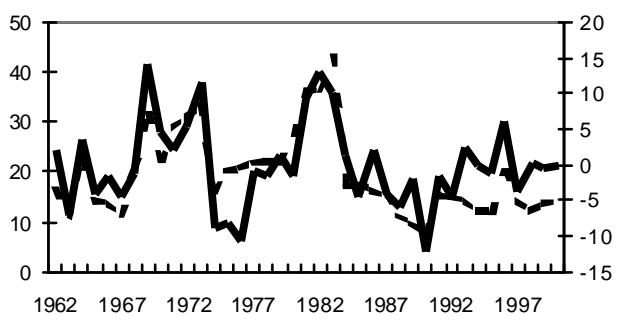

Panel B. Turnover \%

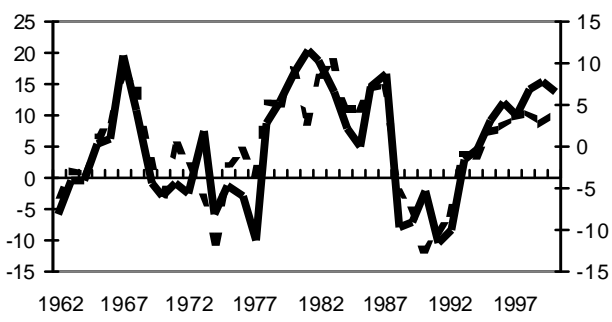

Panel D. Average first-day return

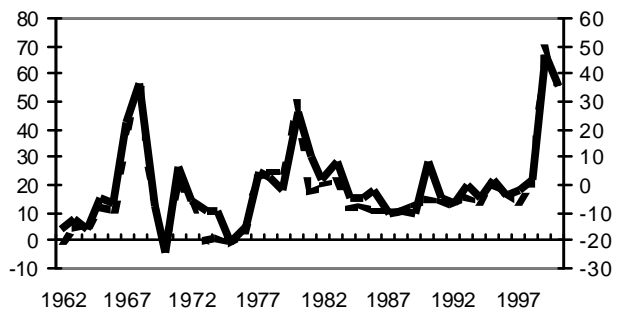

Panel F. Dividend premium

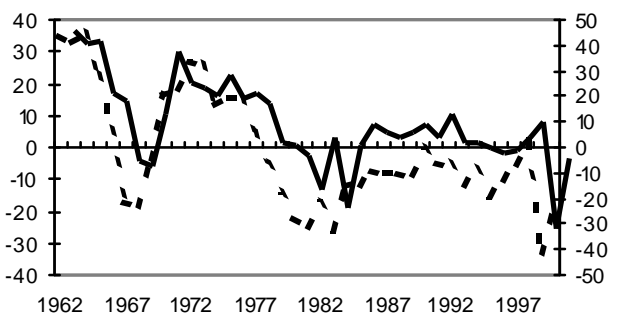

Panel E. Sentiment index (SENTIMENT)

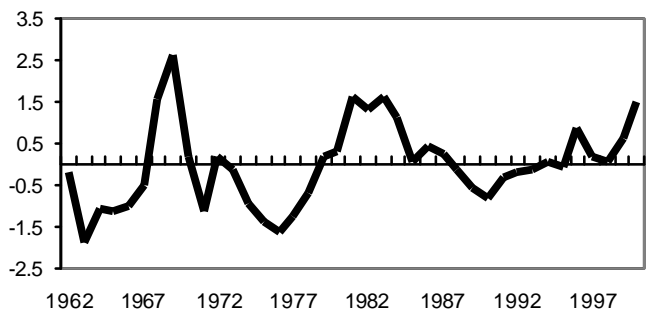


Figure 2. Average Annual Coefficients. Average annual coefficients from monthly univariate regressions of returns on firm characteristics $X$.

$$
R_{i t}=a_{t}+b_{t} X_{i t-1}+e_{i t}
$$

The firm characteristics are size, age, total risk, indicator variables for profitable firms and dividend payers, book-to-market ratio, external finance over assets, and sales growth decile. Size is the log of market equity. Market equity (ME) is price times shares outstanding from CRSP. Age is the number of years since the firm's first appearance on CRSP. Total risk is the annual standard deviation in nonthly returns from CRSP. Earnings (E) is defined as income before extraordinary items (Item 18) plus income statement deferred taxes (Item 50) minus preferred dividends (Item 19). The book-to-market ratio is the log of the ratio of book equity to market equity. Book equity (BE) is defined as shareholders equity (Item 60) plus balance sheet deferred taxes (Item 35). External finance (EF) is equal to the change in assets (Item 6) less the change in retained earnings (Item 36). When the change in retained earnings is not available we use net income (Item 172) less common dividends (Item 21) instead. Sales growth decile is formed using NYSE breakpoints for sales growth. Sales growth is the percentage change in net sales (Item 12). For the last three characteris tics, we analyze the top (solid) and bottom (dashed) seven deciles separately.

Panel A. $\log (\mathrm{ME})$

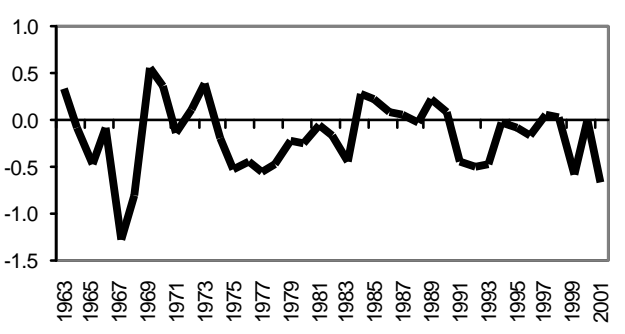

Panel D. E>0

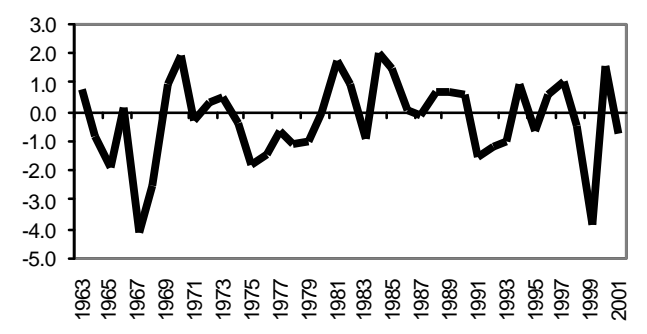

Panel G. EF/A

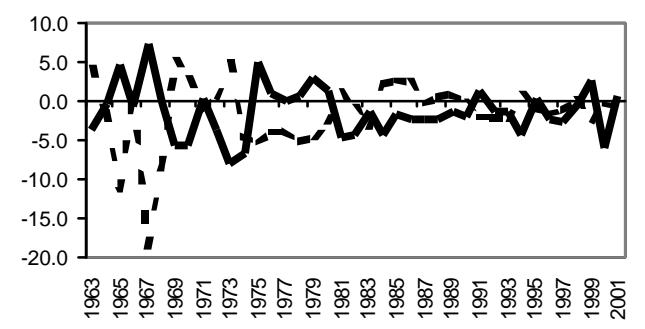

Panel B. Age

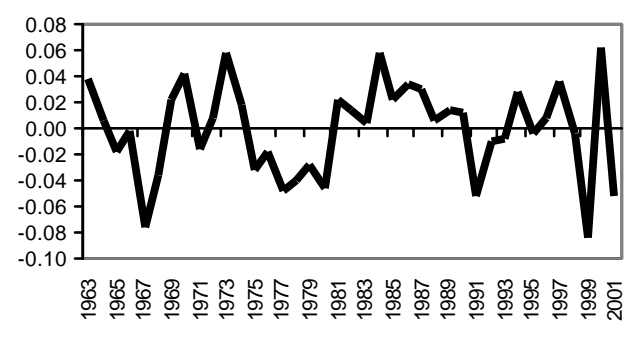

Panel E. D>0

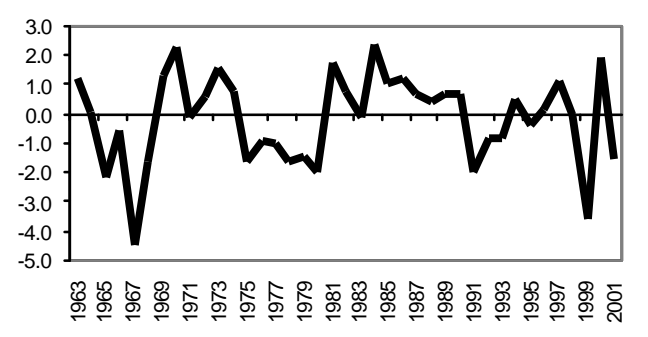

Panel H. GS/10

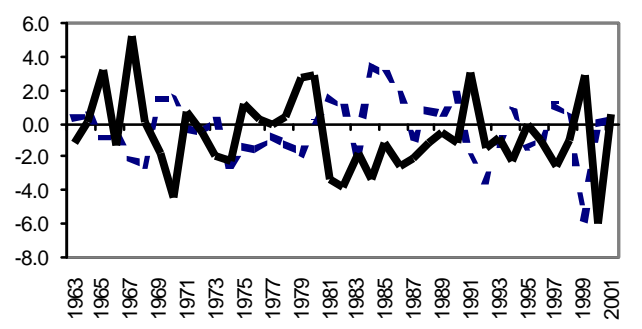

Panel C. Total Risk

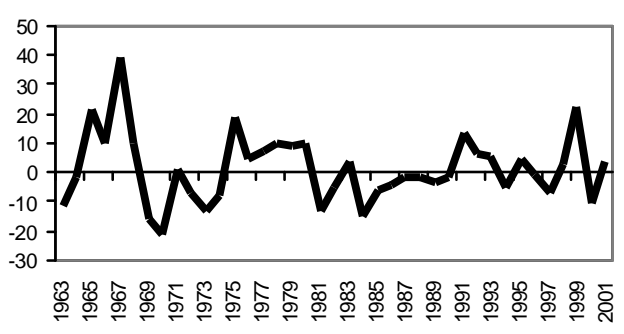

Panel F. $\log (\mathrm{BE} / \mathrm{ME})$

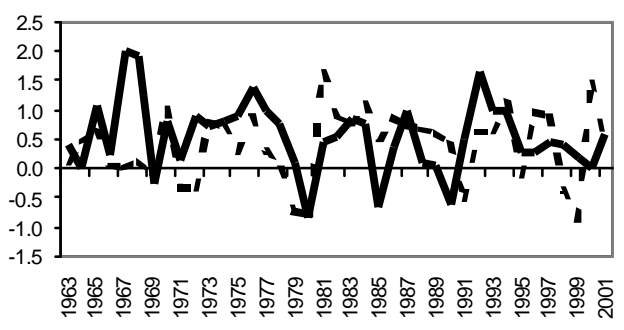


Table 1. Summary Statistics, 1963-2001. Panel A summarizes the returns variables. Returns are measured monthly. Momentum (MOM) is defined as the cumulative return for the eleven-month period between 12 and two months prior to $t$. Panel B summarizes the size, age, and risk characteristics. Size is the log of market equity. Market equity (ME) is price times shares outstanding from CRSP in the June prior to $t$. Age is the number of years between the firm's first appearance on CRSP and $t$. Total risk $(\sigma)$ is the annual standard deviation in monthly returns from CRSP for the 12 months ending in the June prior to $t$. Panel C summarizes profitability variables. The earnings-price ratio is defined for firms with positive earnings. Earnings (E) is defined as income before extraordinary items (Item 18) plus income statement deferred taxes (Item 50) minus preferred dividends (Item 19). Book equity (BE) is defined as shareholders equity (Item 60) plus balance sheet deferred taxes (Item 35). Panel D reports dividend variables. Dividends (D) are equal to dividends per share at the ex date (Item 26) times shares outstanding (Item 25). Panel E reports variables used as proxies for growth opportunities and distress. The book-to-market ratio is the log of the ratio of book equity to market equity. External finance (EF) is equal to the change in assets (Item 6) less the change in retained earnings (Item 36). When the change in retained earnings is not available we use net income (Item 172) less common dividends (Item 21) instead. Sales growth decile is formed using NYSE breakpoints for sales growth. Sales growth is the percentage change in net sales (Item 12). In Panels $\mathrm{C}$ through $\mathrm{E}$, accounting data from the fiscal year ending in $t$-1 are matched to monthly returns from July of year $t$ through June of year $t+1$. All variables are Winsorized at 99.5 and 0.5 percent.

\begin{tabular}{|c|c|c|c|c|c|c|c|c|c|c|}
\hline & \multicolumn{5}{|c|}{ Full Sample } & \multicolumn{5}{|c|}{ Subsample Means } \\
\hline & $\mathbf{N}$ & Mean & SD & Min & Max & $1960 \mathrm{~s}$ & 1970s & 1980s & 1990s & $2000-1$ \\
\hline & \multicolumn{10}{|c|}{ Panel A. Returns } \\
\hline $\mathrm{R}_{t}(\%)$ & $1,398,495$ & 1.38 & 18.69 & -98.13 & 2400.00 & 1.06 & 1.59 & 1.24 & 1.45 & 1.20 \\
\hline \multirow[t]{2}{*}{$\operatorname{MOM}_{t-1}(\%)$} & $1,398,495$ & 13.44 & 60.31 & -85.99 & 359.42 & 21.40 & 12.50 & 14.85 & 12.10 & 12.02 \\
\hline & \multicolumn{10}{|c|}{ Panel B. Size and Age } \\
\hline $\mathrm{ME}_{t-1}(\$ \mathrm{M})$ & $1,398,495$ & 576 & 2,153 & 1 & 21,623 & 392 & 238 & 373 & 807 & 1,412 \\
\hline $\mathrm{Age}_{t}$ (Years) & $1,398,495$ & 13.72 & 13.91 & 0.03 & 69.17 & 16.02 & 12.96 & 13.84 & 13.70 & 14.14 \\
\hline \multirow[t]{2}{*}{$\sigma_{t-1}(\%)$} & $1,375,961$ & 14.21 & 8.92 & 0.00 & 62.39 & 9.40 & 12.58 & 13.68 & 14.77 & 21.59 \\
\hline & \multicolumn{10}{|c|}{ Panel C. Profitability } \\
\hline $\mathrm{E}+/ \mathrm{BE}_{t-1}(\%)$ & $1,398,495$ & 10.62 & 10.31 & 0.00 & 67.14 & 12.13 & 12.09 & 11.29 & 9.27 & 9.09 \\
\hline \multirow[t]{2}{*}{$\mathrm{E}>0_{t-1}$} & $1,398,495$ & 0.76 & 0.42 & 0.00 & 1.00 & 0.95 & 0.91 & 0.77 & 0.68 & 0.63 \\
\hline & \multicolumn{10}{|c|}{ Panel D. Dividend Policy } \\
\hline $\mathrm{D} / \mathrm{BE}_{t-1}(\%)$ & $1,398,495$ & 1.97 & 2.96 & 0.00 & 17.61 & 4.43 & 2.72 & 1.98 & 1.36 & 1.05 \\
\hline \multirow[t]{2}{*}{$\mathrm{D}>0_{t-1}$} & $1,398,495$ & 0.45 & 0.50 & 0.00 & 1.00 & 0.78 & 0.65 & 0.48 & 0.30 & 0.24 \\
\hline & \multicolumn{10}{|c|}{ Panel E. Growth Opportunities and Distress } \\
\hline $\mathrm{BE} / \mathrm{ME}_{t-1}$ & $1,398,495$ & 0.93 & 0.86 & 0.02 & 5.78 & 0.70 & 1.35 & 0.92 & 0.72 & 0.81 \\
\hline $\mathrm{EF} / \mathrm{A}_{t-1}(\%)$ & $1,365,152$ & 11.69 & 24.98 & -69.17 & 131.18 & 7.11 & 6.34 & 10.71 & 14.76 & 19.13 \\
\hline $\mathrm{GS}_{t-1}($ Decile $)$ & $1,349,505$ & 5.93 & 3.19 & 1.00 & 10.00 & 5.65 & 5.66 & 5.97 & 6.12 & 5.90 \\
\hline
\end{tabular}


Table 2. Investor Sentiment. Means, standard deviations, and correlations for measures of investor sentiment. The first measure (CEFD) is the year-end, valueweighted average discount on closed-end mutual funds. The data on prices and net asset values (NAVs) come from Neal and Wheatley (1998) for 1962 through 1993; CDA/Wiesenberger for 1994 through 1998; and turn-of-the-year issues of the Wall Street Journal for 1999 and 2000. The second measure (TURN) is detrended log turnover. Turnover is the ratio of reported share volume to average shares listed from the NYSE Fact Book. We detrend using the past five-year average. The third measure (NIPO) is the annual number of initial public offerings. The fourth measure (RIPO) is the average annual first-day returns of initial public offerings. Both IPO series come from Jay Ritter, updating data analyzed in Ibbotson, Sindelar, and Ritter (1994). The fifth measure (S) is gross annual equity issuance divided by gross annual equity plus debt issuance from Baker and Wurgler (2000). The sixth measure ( $\left.\mathrm{P}^{\mathrm{D}-\mathrm{ND}}\right)$ is the year-end log ratio of the value-weighted average market-to-book ratios of payers and nonpayers from Baker and Wurgler (2003). Turnover, the average annual first-day return, and the dividend premium are lagged one year relative to the other three measures. In the first panel, we present raw data. In the second panel, we regress each measure on the growth in industrial production, the growth in durable, nondurable and services consumption, the growth in employment and a flag for NBER recessions. The adjusted measures are the residuals from these regressions. SENTIMENT is the first principal component of the six orthogonalized measures. a, b, and $\mathrm{c}$ denote statistical significance at $1 \%, 5 \%$, and $10 \%$.

\begin{tabular}{|c|c|c|c|c|c|c|c|c|c|c|c|}
\hline & \multirow[b]{2}{*}{ Mean } & \multirow[b]{2}{*}{ SD } & \multirow[b]{2}{*}{ Min } & \multirow[b]{2}{*}{ Max } & \multicolumn{7}{|c|}{ Correlations } \\
\hline & & & & & SENTIMENT & CEFD & TURN & NIPO & RIPO & $\mathbf{S}$ & PD-ND \\
\hline & \multicolumn{11}{|c|}{ Panel A. Raw data } \\
\hline$\overline{\mathrm{CEFD}_{t}}$ & 8.83 & 8.11 & -10.41 & 23.70 & $-0.60^{\mathrm{a}}$ & 1.00 & & & & & \\
\hline $\operatorname{TURN}_{t-1}$ & 5.21 & 7.94 & -11.60 & 18.66 & $0.69^{\mathrm{a}}$ & $-0.30^{\mathrm{c}}$ & 1.00 & & & & \\
\hline $\mathrm{NIPO}_{t}$ & 358.41 & 262.76 & 9.00 & 953.00 & $0.66^{\mathrm{a}}$ & $-0.57^{\mathrm{a}}$ & $0.38^{\mathrm{b}}$ & 1.00 & & & \\
\hline $\mathrm{RIPO}_{t-1}$ & 16.94 & 14.93 & -1.67 & 69.53 & $0.80^{\mathrm{a}}$ & $-0.41^{\mathrm{b}}$ & $0.50^{\mathrm{a}}$ & $0.35^{\mathrm{b}}$ & 1.00 & & \\
\hline $\mathrm{S}_{t}$ & 19.53 & 8.34 & 7.83 & 43.00 & $0.43^{\mathrm{a}}$ & 0.01 & $0.30^{\mathrm{c}}$ & 0.16 & 0.26 & 1.00 & \\
\hline \multirow[t]{2}{*}{$\mathrm{P}_{t-1}^{\mathrm{D}-\mathrm{ND}}$} & 0.20 & 18.67 & -33.17 & 36.06 & $-0.76^{\mathrm{a}}$ & $0.53^{\mathrm{a}}$ & $-0.50^{\mathrm{a}}$ & $-0.56^{\mathrm{a}}$ & $-0.58^{\mathrm{a}}$ & -0.12 & 1.00 \\
\hline & \multicolumn{11}{|c|}{ Panel B. Controlling for macroeconomic conditions } \\
\hline $\mathrm{CEFD}_{t}$ & 0.00 & 6.15 & -18.33 & 9.16 & $-0.64^{\mathrm{a}}$ & 1.00 & & & & & \\
\hline TURN $_{t-1}$ & 0.00 & 6.73 & -11.31 & 11.45 & $0.72^{\mathrm{a}}$ & $-0.29^{\mathrm{c}}$ & 1.00 & & & & \\
\hline $\mathrm{NIPO}_{t}$ & 0.00 & 226.30 & -435.98 & 484.15 & $0.74^{\mathrm{a}}$ & $-0.46^{\mathrm{a}}$ & $0.39^{\mathrm{b}}$ & 1.00 & & & \\
\hline $\mathrm{RIPO}_{t-1}$ & 0.00 & 14.31 & -23.55 & 46.54 & $0.83^{\mathrm{a}}$ & $-0.45^{\mathrm{a}}$ & $0.53^{\mathrm{a}}$ & $0.44^{\mathrm{a}}$ & 1.00 & & \\
\hline $\mathrm{S}_{t}$ & 0.00 & 6.15 & -12.17 & 14.29 & $0.66^{\mathrm{a}}$ & $-0.40^{\mathrm{b}}$ & $0.32^{\mathrm{b}}$ & $0.50^{\mathrm{a}}$ & $0.47^{\mathrm{a}}$ & 1.00 & \\
\hline $\mathrm{P}_{t-1}^{\mathrm{D}-\mathrm{ND}}$ & 0.00 & 16.89 & -43.20 & 35.96 & $-0.77^{\mathrm{a}}$ & $0.28^{\mathrm{c}}$ & $-0.60^{\mathrm{a}}$ & $-0.46^{\mathrm{a}}$ & $-0.68^{\mathrm{a}}$ & $-0.28^{\mathrm{c}}$ & 1.00 \\
\hline
\end{tabular}


Table 3a. Two-way Sorts: Closed-End Fund Discount and Firm Characteristics. For each month, we form ten portfolios according to the NYSE breakpoints of firm size (ME), age, total risk, earnings-book ratio for profitable firms (E/BE), dividend-book ratio for dividend payers (D/BE), book-to-market ratio (BE/ME), external finance over assets (EF/A), and sales growth (GS). We also calculate portfolio returns for unprofitable firms and nonpayers. We then report average portfolio returns over months where the standardized CEFD (orthogonalized to macroeconomic conditions) from the previous year-end is positive, negative, and the difference between the two averages.

\begin{tabular}{|c|c|c|c|c|c|c|c|c|c|c|c|c|c|c|c|c|}
\hline & \multirow[t]{2}{*}{$C E F D_{t-1}$} & \multicolumn{11}{|c|}{ Decile } & \multicolumn{4}{|c|}{ Overall } \\
\hline & & $\leq \mathbf{0}$ & 1 & 2 & 3 & 4 & 5 & 6 & 7 & 8 & 9 & 10 & $10-1$ & $10-5$ & $5-1$ & $\begin{array}{l}>0 \\
\leq 0\end{array}$ \\
\hline \multirow[t]{3}{*}{ ME } & Positive & & 2.39 & 1.93 & 1.81 & 1.80 & 1.83 & 1.63 & 1.62 & 1.50 & 1.38 & 1.31 & -1.08 & -0.52 & -0.57 & \\
\hline & Negative & & 0.46 & 0.21 & 0.36 & 0.24 & 0.54 & 0.34 & 0.45 & 0.55 & 0.47 & 0.38 & -0.08 & -0.16 & 0.08 & \\
\hline & Difference & & 1.93 & 1.73 & 1.46 & 1.56 & 1.29 & 1.30 & 1.17 & 0.95 & 0.91 & 0.93 & -1.00 & -0.35 & -0.65 & \\
\hline \multirow[t]{3}{*}{ Age } & Positive & & 1.95 & 1.99 & 2.06 & 1.94 & 2.03 & 1.98 & 1.57 & 1.67 & 1.63 & 1.48 & -0.48 & -0.55 & 0.08 & \\
\hline & Negative & & -0.24 & 0.48 & 0.67 & 0.46 & 0.64 & 0.64 & 0.65 & 0.66 & 0.58 & 0.72 & 0.96 & 0.08 & 0.88 & \\
\hline & Difference & & 2.20 & 1.51 & 1.39 & 1.47 & 1.40 & 1.34 & 0.91 & 1.01 & 1.05 & 0.76 & -1.44 & -0.64 & -0.80 & \\
\hline \multirow[t]{3}{*}{$\sigma$} & Positive & & 1.35 & 1.51 & 1.52 & 1.68 & 1.82 & 1.92 & 1.91 & 2.08 & 2.17 & 2.37 & 1.01 & 0.54 & 0.47 & \\
\hline & Negative & & 0.84 & 0.84 & 0.78 & 0.66 & 0.69 & 0.52 & 0.49 & 0.39 & 0.41 & 0.07 & -0.77 & -0.62 & -0.15 & \\
\hline & Difference & & 0.51 & 0.67 & 0.74 & 1.02 & 1.13 & 1.40 & 1.42 & 1.69 & 1.76 & 2.29 & 1.78 & 1.16 & 0.62 & \\
\hline \multirow[t]{3}{*}{$\mathrm{E} / \mathrm{BE}$} & Positive & 2.48 & 2.21 & 2.08 & 2.10 & 1.92 & 1.79 & 1.95 & 1.90 & 1.88 & 1.77 & 1.87 & -0.34 & 0.08 & -0.42 & -0.62 \\
\hline & Negative & 0.24 & 0.53 & 0.65 & 0.89 & 0.53 & 0.48 & 0.49 & 0.38 & 0.50 & 0.48 & 0.36 & -0.17 & -0.11 & -0.06 & 0.23 \\
\hline & Difference & 2.24 & 1.68 & 1.44 & 1.21 & 1.39 & 1.31 & 1.46 & 1.52 & 1.38 & 1.29 & 1.51 & -0.17 & 0.20 & -0.36 & -0.85 \\
\hline \multirow[t]{3}{*}{$\mathrm{D} / \mathrm{BE}$} & Positive & 2.35 & 2.07 & 1.91 & 1.92 & 1.77 & 1.72 & 1.59 & 1.52 & 1.46 & 1.44 & 1.37 & -0.70 & -0.34 & -0.35 & -0.63 \\
\hline & Negative & 0.12 & 0.60 & 0.52 & 0.72 & 0.47 & 0.61 & 0.67 & 0.77 & 0.70 & 0.72 & 0.81 & 0.21 & 0.20 & 0.01 & 0.53 \\
\hline & Difference & 2.23 & 1.47 & 1.39 & 1.19 & 1.30 & 1.11 & 0.92 & 0.75 & 0.75 & 0.71 & 0.56 & -0.91 & -0.54 & -0.36 & -1.16 \\
\hline \multirow[t]{3}{*}{$\mathrm{BE} / \mathrm{ME}$} & Positive & & 1.47 & 1.71 & 1.77 & 1.86 & 1.86 & 1.93 & 2.12 & 2.11 & 2.33 & 2.58 & 1.10 & 0.72 & 0.39 & \\
\hline & Negative & & -0.26 & 0.09 & 0.35 & 0.38 & 0.57 & 0.67 & 0.67 & 0.76 & 0.89 & 0.94 & 1.21 & 0.37 & 0.83 & \\
\hline & Difference & & 1.74 & 1.62 & 1.42 & 1.49 & 1.29 & 1.26 & 1.45 & 1.35 & 1.44 & 1.64 & -0.10 & 0.34 & -0.44 & \\
\hline \multirow[t]{3}{*}{$\mathrm{EF} / \mathrm{A}$} & Positive & & 2.52 & 2.19 & 2.08 & 1.98 & 1.83 & 1.88 & 1.88 & 1.79 & 1.92 & 1.66 & -0.86 & -0.17 & -0.69 & \\
\hline & Negative & & 0.76 & 0.75 & 0.85 & 0.77 & 0.73 & 0.62 & 0.39 & 0.38 & 0.25 & -0.47 & -1.23 & -1.20 & -0.03 & \\
\hline & Difference & & 1.76 & 1.44 & 1.23 & 1.21 & 1.10 & 1.26 & 1.49 & 1.42 & 1.67 & 2.12 & 0.37 & 1.02 & -0.66 & \\
\hline \multirow[t]{3}{*}{ GS } & Positive & & 2.36 & 2.04 & 1.97 & 1.79 & 1.82 & 1.88 & 1.99 & 2.08 & 1.90 & 1.81 & -0.56 & -0.01 & -0.54 & \\
\hline & Negative & & 0.66 & 0.60 & 0.58 & 0.65 & 0.62 & 0.66 & 0.68 & 0.56 & 0.35 & -0.42 & -1.09 & -1.05 & -0.04 & \\
\hline & Difference & & 1.70 & 1.44 & 1.38 & 1.14 & 1.20 & 1.21 & 1.31 & 1.52 & 1.55 & 2.23 & 0.53 & 1.04 & -0.50 & \\
\hline
\end{tabular}


Table 3b. Two-way Sorts: Sentiment Index and Firm Characteristics. For each month, we form ten portfolios according to the NYSE breakpoints of firm size (ME), age, total risk, earnings-book ratio for profitable firms (E/BE), dividend-book ratio for dividend payers (D/BE), book-to-market ratio (BE/ME), external finance over assets (EF/A), and sales growth (GS). We also calculate portfolio returns for unprofitable firms and nonpayers. We then report average portfolio returns over months where the standardized SENTIMENT (orthogonalized to macroeconomic conditions) from the previous year end is positive, negative, and the difference between the two averages.

\begin{tabular}{|c|c|c|c|c|c|c|c|c|c|c|c|c|c|c|c|c|}
\hline & \multirow[t]{2}{*}{ SENTIMENT $_{t-1}$} & \multicolumn{11}{|c|}{ Decile } & \multicolumn{4}{|c|}{ Overall } \\
\hline & & $\leq \mathbf{0}$ & 1 & 2 & 3 & 4 & 5 & 6 & 7 & 8 & 9 & 10 & $10-1$ & $10-5$ & $5-1$ & $\begin{array}{l}>0- \\
\leq 0\end{array}$ \\
\hline \multirow[t]{3}{*}{$\mathrm{ME}$} & Positive & & 0.88 & 0.81 & 0.79 & 0.80 & 0.95 & 0.85 & 1.09 & 1.01 & 0.99 & 0.97 & 0.08 & 0.01 & 0.07 & \\
\hline & Negative & & 2.33 & 1.66 & 1.65 & 1.52 & 1.66 & 1.36 & 1.21 & 1.23 & 1.03 & 0.91 & -1.43 & -0.75 & -0.68 & \\
\hline & Difference & & -1.45 & -0.84 & -0.86 & -0.72 & -0.71 & -0.51 & -0.13 & -0.22 & -0.04 & 0.06 & 1.51 & 0.77 & 0.74 & \\
\hline \multirow[t]{3}{*}{ Age } & Positive & & 0.35 & 0.96 & 1.09 & 1.03 & 1.29 & 1.26 & 1.00 & 1.13 & 1.06 & 1.07 & 0.72 & -0.23 & 0.95 & \\
\hline & Negative & & 1.75 & 1.80 & 1.89 & 1.63 & 1.63 & 1.62 & 1.39 & 1.39 & 1.36 & 1.27 & -0.47 & -0.36 & -0.11 & \\
\hline & Difference & & -1.40 & -0.84 & -0.80 & -0.60 & -0.34 & -0.35 & -0.40 & -0.25 & -0.30 & -0.20 & 1.20 & 0.13 & 1.06 & \\
\hline \multirow[t]{3}{*}{$\sigma$} & Positive & & 1.26 & 1.26 & 1.09 & 1.11 & 1.16 & 1.02 & 0.99 & 0.97 & 0.89 & 0.61 & -0.65 & -0.55 & -0.09 & \\
\hline & Negative & & 1.04 & 1.22 & 1.35 & 1.42 & 1.57 & 1.69 & 1.68 & 1.81 & 2.01 & 2.25 & 1.21 & 0.69 & 0.53 & \\
\hline & Difference & & 0.22 & 0.04 & -0.26 & -0.31 & -0.40 & -0.67 & -0.70 & -0.83 & -1.12 & -1.64 & -1.86 & -1.24 & -0.62 & \\
\hline \multirow[t]{3}{*}{$\mathrm{E} / \mathrm{BE}$} & Positive & 0.62 & 0.72 & 0.98 & 0.91 & 0.90 & 0.94 & 0.89 & 0.93 & 1.03 & 1.04 & 0.91 & 0.20 & -0.03 & 0.23 & 0.32 \\
\hline & Negative & 2.51 & 2.33 & 2.02 & 2.30 & 1.82 & 1.57 & 1.82 & 1.64 & 1.62 & 1.45 & 1.60 & -0.72 & 0.03 & -0.76 & -0.85 \\
\hline & Difference & -1.89 & -1.61 & -1.04 & -1.39 & -0.92 & -0.63 & -0.93 & -0.72 & -0.59 & -0.41 & -0.69 & 0.92 & -0.06 & 0.98 & 1.16 \\
\hline \multirow[t]{3}{*}{$\mathrm{D} / \mathrm{BE}$} & Positive & 0.62 & 0.99 & 1.00 & 1.19 & 0.95 & 1.08 & 1.05 & 1.16 & 1.13 & 1.08 & 1.02 & 0.04 & -0.06 & 0.09 & 0.45 \\
\hline & Negative & 2.26 & 1.96 & 1.69 & 1.68 & 1.53 & 1.46 & 1.39 & 1.27 & 1.17 & 1.21 & 1.27 & -0.69 & -0.19 & -0.50 & -0.77 \\
\hline & Difference & -1.64 & -0.97 & -0.70 & -0.49 & -0.58 & -0.38 & -0.33 & -0.11 & -0.04 & -0.13 & -0.25 & 0.73 & 0.13 & 0.59 & 1.21 \\
\hline \multirow[t]{3}{*}{$\mathrm{BE} / \mathrm{ME}$} & Positive & & 0.26 & 0.77 & 0.93 & 0.97 & 1.06 & 1.15 & 1.15 & 1.19 & 1.31 & 1.36 & 1.10 & 0.30 & 0.80 & \\
\hline & Negative & & 1.27 & 1.35 & 1.47 & 1.55 & 1.62 & 1.68 & 1.91 & 1.94 & 2.19 & 2.47 & 1.19 & 0.85 & 0.35 & \\
\hline & Difference & & -1.01 & -0.58 & -0.54 & -0.58 & -0.56 & -0.53 & -0.76 & -0.75 & -0.88 & -1.11 & -0.10 & -0.55 & 0.45 & \\
\hline \multirow[t]{3}{*}{$\mathrm{EF} / \mathrm{A}$} & Positive & & 1.23 & 1.14 & 1.32 & 1.26 & 1.21 & 1.20 & 1.06 & 0.90 & 0.79 & 0.15 & -1.07 & -1.06 & -0.01 & \\
\hline & Negative & & 2.39 & 2.07 & 1.84 & 1.71 & 1.56 & 1.54 & 1.49 & 1.54 & 1.69 & 1.44 & -0.95 & -0.12 & -0.82 & \\
\hline & Difference & & -1.16 & -0.93 & -0.52 & -0.45 & -0.35 & -0.34 & -0.43 & -0.64 & -0.90 & -1.28 & -0.12 & -0.94 & 0.81 & \\
\hline \multirow[t]{3}{*}{ GS } & Positive & & 0.98 & 1.17 & 1.21 & 1.13 & 1.19 & 1.17 & 1.23 & 1.13 & 0.89 & 0.18 & -0.80 & -1.02 & 0.21 & \\
\hline & Negative & & 2.36 & 1.74 & 1.60 & 1.54 & 1.48 & 1.60 & 1.69 & 1.79 & 1.65 & 1.62 & -0.74 & 0.14 & -0.88 & \\
\hline & Difference & & -1.37 & -0.58 & -0.39 & -0.41 & -0.28 & -0.43 & -0.46 & -0.66 & -0.76 & -1.44 & -0.07 & -1.16 & 1.09 & \\
\hline
\end{tabular}


Table 4. Baseline Regressions, Monthly Returns. Average coefficients and t-statistics from monthly regressions of returns on firm characteristics (X), size $(\log (\mathrm{ME}))$, book-to-market $(\log (\mathrm{BE} / \mathrm{ME}))$, and momentum $(\mathrm{MOM})$.

$$
R_{i t}=a_{t}+b_{t} X_{i t-1}+s_{t} \log (M E)_{i t-1}+h_{t} \log (B E / M E)_{i t-1}+m_{t} M O M_{i t-1}+e_{i t}
$$

We only report the average of $b_{t}$. The firm characteristics are firm size $(\log (\mathrm{ME}))$, age $(\log (\mathrm{Age}))$, total risk $(\sigma)$, an indicator variable for profitable firms $(\mathrm{E}>0)$ and dividend payers $(\mathrm{D}>0)$, book-to-market ratio $(\log (\mathrm{BE} / \mathrm{ME})$ ), external finance over assets (EF/A), and sales growth decile (GS). The first panel shows univariate results. The second panel includes book-to-market, size, and momentum as control variables. Standard errors are equal to the time series standard deviation of $b_{t}$ divided by the number of months.

\begin{tabular}{|c|c|c|c|c|c|c|c|c|c|c|c|c|c|c|c|}
\hline \multicolumn{2}{|c|}{$M E$} & \multicolumn{2}{|c|}{ Age } & \multicolumn{2}{|c|}{$\sigma$} & \multicolumn{2}{|c|}{$E>0$} & \multicolumn{2}{|c|}{$D>0$} & \multicolumn{2}{|c|}{$B E / M E$} & \multicolumn{2}{|c|}{$E F / A$} & \multicolumn{2}{|c|}{$G S / 10$} \\
\hline $\mathbf{s}$ & $\mathbf{t}(\mathbf{s})$ & b & t(b) & b & $\mathbf{t}(\mathbf{b})$ & b & $\mathbf{t}(\mathbf{b})$ & b & t(b) & $\mathbf{h}$ & $\mathbf{t}(\mathbf{h})$ & b & t(b) & b & $\mathbf{t}(\mathbf{b})$ \\
\hline \multicolumn{16}{|c|}{ Panel A. Univariate } \\
\hline-0.17 & {$[-3.3]$} & 0.04 & {$[0.7]$} & 1.45 & {$[1.0]$} & -0.26 & {$[-1.3]$} & -0.17 & {$[-0.8]$} & 0.47 & {$[6.5]$} & -1.64 & {$[-6.7]$} & -0.59 & {$[-4.6]$} \\
\hline \multicolumn{16}{|c|}{ Panel B. Controlling for Book-to-Market, Size, and Momentum } \\
\hline-0.18 & {$[-3.4]$} & 0.10 & {$[2.8]$} & & & & & & & 0.31 & [4.4] & & & & \\
\hline-0.16 & {$[-3.7]$} & & & -0.40 & {$[-0.4]$} & & & & & 0.34 & {$[5.4]$} & & & & \\
\hline-0.16 & {$[-3.3]$} & & & & & -0.05 & {$[-0.4]$} & & & 0.35 & [4.9] & & & & \\
\hline-0.16 & {$[-3.5]$} & & & & & & & 0.05 & {$[0.4]$} & 0.34 & {$[5.1]$} & & & & \\
\hline-0.14 & {$[-2.4]$} & & & & & & & & & 0.52 & {$[6.6]$} & & & & \\
\hline-0.16 & {$[-3.0]$} & & & & & & & & & 0.26 & {$[3.8]$} & -1.16 & {$[-6.8]$} & & \\
\hline-0.15 & {$[-2.8]$} & & & & & & & & & 0.32 & {$[4.4]$} & & & -0.26 & {$[-2.7]$} \\
\hline
\end{tabular}


Table 5. Time Series Regressions, Monthly Returns Coefficients. Two-stage regression. In the first stage, we compute coefficients from monthly regressions of returns on firm characteristics $(\mathrm{X})$, size $(\log (\mathrm{ME}))$, book-to-market $(\log (\mathrm{BE} / \mathrm{ME}))$, and momentum $(\mathrm{MOM})$.

$$
R_{i t}=a_{t}+b_{t} X_{i t-1}+s_{t} \log (M E)_{i t-1}+h_{t} \log (B E / M E)_{i t-1}+m_{t} M O M_{i t-1}+e_{i t}
$$

The firm characteristics are firm size $(\log (\mathrm{ME}))$, age $(\log ($ Age $))$, total risk $(\sigma)$, an indicator variable for profitable firms $(\mathrm{E}>0)$ and dividend payers $(\mathrm{D}>0)$, bookto-market ratio $(\log (\mathrm{BE} / \mathrm{ME}))$, external finance over assets (EF/A), and sales growth decile (GS). When we analyze growth opportunities, we exclude the top (bottom) three deciles for book-to-market ratio (external finance, sales growth). When we analyze distress, we exclude the bottom (top) three deciles for book-tomarket ratio (external finance, sales growth). In the second stage, we regress the monthly coefficients $b_{t}$ on measures of investor sentiment, each standardized to have unit variance.

$$
\hat{b}_{t}=c+d S E N T I M E N T_{t-1}+u_{t}
$$

Coefficients are matched to the closed-end fund discount (CEFD), the number of IPOs (NIPO), and the equity share (S) for the calendar year one year before $t$ Coefficeints are matched to detrended log turnover (TURN), the average annual first-day return (RIPO), and the dividend premium ( $\mathrm{P}^{\mathrm{D}-\mathrm{ND}}$ ) for the calendar year two years before $t$. All sentiment measures are orthogonalized to macroeconomic conditions. The first seven columns show univariate results. The last column includes size, book-to-market, and momentum as control variables in the first-stage regression and uses the sentiment index in the second stage. Bootstrap p-

\begin{tabular}{|c|c|c|c|c|c|c|c|c|c|c|c|c|c|c|c|c|}
\hline & \multicolumn{2}{|c|}{$C E F D_{t-1}$} & \multicolumn{2}{|c|}{$T U R N_{t-2}$} & \multicolumn{2}{|c|}{$N I P O_{t-1}$} & \multicolumn{2}{|c|}{$R I P O_{t-2}$} & \multicolumn{2}{|c|}{$S_{t-1}$} & \multicolumn{2}{|c|}{$P_{t-2}^{D-N D}$} & \multicolumn{2}{|c|}{ SENTIMENT $_{t-1}$} & \multicolumn{2}{|c|}{$\begin{array}{l}\text { SENTIMENT } T_{t-1} \\
\text { Controlling for } \\
M E, B E / M E, \\
\text { and } M O M \\
\end{array}$} \\
\hline & d & $\mathbf{p}(\mathbf{d})$ & d & $\mathbf{p}(\mathbf{d})$ & d & $\mathbf{p}(\mathbf{d})$ & d & $\mathbf{p}(\mathbf{d})$ & d & $\mathbf{p}(\mathbf{d})$ & d & $\mathbf{p}(\mathbf{d})$ & d & $\mathbf{p}(\mathbf{d})$ & d & $\mathbf{p}(\mathbf{d})$ \\
\hline $\mathrm{ME}$ & -0.2 & {$[.00]$} & 0.1 & {$[.10]$} & 0.2 & {$[.00]$} & 0.1 & {$[.18]$} & 0.1 & {$[.06]$} & -0.0 & [.49] & 0.1 & {$[.02]$} & 0.1 & {$[.03]$} \\
\hline Age & -0.2 & {$[.01]$} & 0.1 & {$[.14]$} & 0.3 & {$[.00]$} & 0.1 & {$[.13]$} & 0.2 & {$[.01]$} & -0.0 & [.59] & 0.2 & {$[.01]$} & 0.0 & {$[.51]$} \\
\hline$\sigma$ & 6.7 & {$[.00]$} & -3.6 & {$[.07]$} & -7.5 & {$[.00]$} & -4.8 & {$[.01]$} & -5.0 & {$[.01]$} & 3.0 & [.16] & -6.4 & {$[.00]$} & -3.5 & {$[.01]$} \\
\hline$E>0$ & -0.7 & {$[.00]$} & 0.5 & {$[.03]$} & 0.9 & {$[.00]$} & 0.5 & {$[.03]$} & 0.5 & {$[.03]$} & -0.4 & [.09] & 0.7 & {$[.00]$} & 0.4 & {$[.01]$} \\
\hline $\mathrm{D}>0$ & -0.8 & {$[.00]$} & 0.5 & {$[.06]$} & 1.0 & {$[.00]$} & 0.4 & {$[.09]$} & 0.6 & {$[.01]$} & -0.3 & [.31] & 0.7 & {$[.00]$} & 0.4 & {$[.00]$} \\
\hline $\mathrm{BE} / \mathrm{ME}$ & -0.0 & {$[.65]$} & 0.1 & {$[.47]$} & 0.1 & {$[.13]$} & 0.0 & {$[.74]$} & 0.1 & [.16] & -0.0 & [.98] & 0.1 & [.41] & 0.2 & [.09] \\
\hline $\mathrm{EF} / \mathrm{A}$ & 0.6 & {$[.02]$} & -0.1 & {$[.73]$} & -0.6 & {$[.03]$} & -0.2 & [.49] & -0.8 & {$[.00]$} & 0.0 & [.97] & -0.4 & {$[.15]$} & -0.3 & [.19] \\
\hline GS & 0.2 & {$[.15]$} & -0.1 & {$[.51]$} & -0.3 & {$[.05]$} & -0.2 & {$[.31]$} & -0.3 & {$[.07]$} & 0.1 & [.67] & -0.2 & {$[.15]$} & -0.1 & [.44] \\
\hline BE/ME (1-7) & -0.1 & {$[.29]$} & 0.1 & {$[.17]$} & 0.3 & {$[.01]$} & 0.1 & {$[.31]$} & 0.2 & [.09] & -0.1 & [.41] & 0.2 & {$[.09]$} & 0.2 & {$[.05]$} \\
\hline EF/A (4-10) & 1.8 & {$[.00]$} & -0.7 & {$[.20]$} & -1.9 & {$[.00]$} & -0.9 & {$[.06]$} & -1.5 & {$[.01]$} & 0.6 & {$[.31]$} & -1.6 & {$[.00]$} & -0.8 & {$[.03]$} \\
\hline GS (4-10) & 0.1 & {$[.00]$} & -0.1 & {$[.03]$} & -0.1 & {$[.00]$} & -0.1 & {$[.04]$} & -0.1 & {$[.01]$} & 0.1 & [.10] & -0.1 & {$[.00]$} & -0.1 & {$[.01]$} \\
\hline BE/ME (4-10) & 0.1 & {$[.26]$} & -0.1 & {$[.21]$} & -0.1 & {$[.16]$} & -0.1 & {$[.46]$} & 0.0 & {$[.91]$} & 0.2 & [.15] & -0.1 & [.18] & 0.0 & [.70] \\
\hline $\mathrm{EF} / \mathrm{A}(1-7)$ & -2.1 & {$[.00]$} & 1.1 & [.09] & 2.4 & {$[.00]$} & 1.4 & {$[.04]$} & 0.7 & [.33] & -1.4 & [.07] & 2.0 & {$[.01]$} & 0.9 & [.02] \\
\hline GS (1-7) & -0.1 & {$[.02]$} & 0.1 & {$[.03]$} & 0.1 & {$[.00]$} & 0.0 & [.11] & 0.0 & [.26] & -0.0 & [.10] & 0.1 & {$[.02]$} & 0.0 & [.08] \\
\hline
\end{tabular}
values are in braces. 
Table 6. Time Series Regressions, Portfolios. Regressions of long-short portfolio returns on measures of sentiment (S), each standardized to have unit variance, the market risk premium (RMRF), the Fama-French factors (HML and SMB), and a momentum factor (UMD).

$$
R_{X_{i t}=h i g h, t}-R_{X_{i t}=l o w, t}=c+d S E N T I M E N T_{t-1}+\beta R M R F_{t}+s S M B_{t}+h H M L_{t}+m U M D_{t}+u_{t}
$$

The long-short portfolios are formed based on firm characteristics (X): firm size (ME), age, total risk ( $\sigma$ ), profitability (E), dividends (D), book-to-market ratio (BE/ME), external finance over assets (EF/A), and sales growth decile (GS). High is defined as a firm in the top three NYSE deciles; low is defined as a firm in the bottom three NYSE deciles; medium is defined as a firm in the middle four NYSE deciles. Monthly returns are matched to the closed-end fund discount (CEFD), the number of IPOs (NIPO), and the equity share (S) for the calendar year one year before $t$. Monthly returns are matched to detrended log turnover (TURN), the average annual first-day return (RIPO), and the dividend premium ( $\mathrm{P}^{\mathrm{D}-\mathrm{ND}}$ ) for the calendar year two years before $t$. All sentiment measures are orthogonalized to macroeconomic conditions. The first seven columns show univariate results. The last column includes RMRF, SMB, HML, and UMD as control variables. Bootstrap p-values are in braces.

\begin{tabular}{|c|c|c|c|c|c|c|c|c|c|c|c|c|c|c|c|c|c|}
\hline & & \multicolumn{2}{|c|}{$C E F D_{t-1}$} & \multicolumn{2}{|c|}{$T U R N_{t-2}$} & \multicolumn{2}{|c|}{$N I P O_{t-1}$} & \multicolumn{2}{|c|}{$R I P O_{t-2}$} & \multicolumn{2}{|c|}{$S_{t-1}$} & \multicolumn{2}{|c|}{$P_{t-2}{ }^{D-N D}$} & \multicolumn{2}{|c|}{ SENTIMENT $_{t-1}$} & \multicolumn{2}{|c|}{$\begin{array}{l}\text { SENTIMENT } \\
\text { Controlling for } \\
M E, B E / M E, \\
\text { and } M O M \\
\end{array}$} \\
\hline & & d & $\mathbf{p}(\mathbf{d})$ & d & $\mathbf{p}(\mathbf{d})$ & d & $\mathbf{p}(\mathbf{d})$ & d & $\mathbf{p}(\mathbf{d})$ & d & $\mathbf{p}(\mathbf{d})$ & d & $\mathbf{p}(\mathbf{d})$ & d & $p(d)$ & d & $\mathbf{p}(\mathbf{d})$ \\
\hline $\mathrm{ME}$ & SMB & 0.4 & {$[.01]$} & -0.2 & [.39] & -0.6 & {$[.00]$} & -0.1 & [.48] & -0.3 & [.13] & 0.1 & [.61] & -0.3 & {$[.07]$} & -0.2 & [.18] \\
\hline Age & High-Low & -0.6 & {$[.02]$} & 0.3 & [.19] & 0.9 & [.00] & 0.2 & {$[.25]$} & 0.6 & [.01] & -0.1 & [.57] & 0.6 & {$[.02]$} & 0.2 & [.09] \\
\hline$\sigma$ & High-Low & 0.9 & {$[.00]$} & -0.5 & {$[.06]$} & -1.0 & {$[.00]$} & -0.4 & [.12] & -0.7 & {$[.02]$} & 0.4 & [.28] & -0.8 & {$[.01]$} & -0.4 & {$[.03]$} \\
\hline $\mathrm{E}$ & $>0-<0$ & -0.7 & {$[.00]$} & 0.5 & {$[.05]$} & 0.9 & [.00] & 0.4 & [.07] & 0.5 & [.03] & -0.4 & [.09] & 0.7 & {$[.00]$} & 0.5 & {$[.02]$} \\
\hline D & $>0-=0$ & -0.8 & {$[.00]$} & 0.5 & {$[.07]$} & 1.0 & [.00] & 0.4 & [.10] & 0.6 & [.01] & -0.3 & [.28] & 0.7 & {$[.00]$} & 0.4 & {$[.01]$} \\
\hline $\mathrm{BE} / \mathrm{ME}$ & HML & -0.1 & [.45] & 0.1 & [.49] & 0.2 & [.23] & 0.2 & [.19] & 0.2 & [.20] & 0.0 & [.89] & 0.2 & [.30] & 0.1 & [.67] \\
\hline $\mathrm{EF} / \mathrm{A}$ & High-Low & 0.2 & [.15] & -0.1 & [.63] & -0.3 & {$[.01]$} & -0.1 & [.36] & -0.3 & {$[.01]$} & 0.1 & [.37] & -0.2 & [.08] & -0.1 & {$[.30]$} \\
\hline GS & High-Low & 0.1 & {$[.21]$} & -0.0 & {$[.71]$} & -0.2 & {$[.07]$} & -0.1 & [.33] & -0.2 & [.14] & 0.0 & [.69] & -0.2 & [.17] & -0.1 & {$[.45]$} \\
\hline $\mathrm{BE} / \mathrm{ME}$ & Low-Medium & -0.1 & {$[.25]$} & 0.2 & {$[.23]$} & 0.3 & {$[.02]$} & 0.1 & {$[.38]$} & 0.2 & {$[.06]$} & -0.1 & [.48] & 0.2 & {$[.09]$} & 0.1 & {$[.31]$} \\
\hline $\mathrm{EF} / \mathrm{A}$ & High-Medium & 0.4 & {$[.01]$} & -0.2 & {$[.07]$} & -0.5 & {$[.00]$} & -0.2 & [.09] & -0.4 & {$[.01]$} & 0.2 & [.10] & -0.4 & {$[.00]$} & -0.2 & {$[.01]$} \\
\hline GS & High-Medium & 0.4 & {$[.00]$} & -0.3 & {$[.04]$} & -0.5 & {$[.00]$} & -0.3 & {$[.04]$} & -0.3 & {$[.02]$} & 0.2 & [.13] & -0.4 & {$[.00]$} & -0.2 & {$[.01]$} \\
\hline $\mathrm{BE} / \mathrm{ME}$ & High-Medium & 0.1 & [.39] & -0.1 & [.44] & -0.1 & {$[.26]$} & -0.0 & [.69] & 0.0 & [.89] & 0.1 & [.18] & -0.1 & [.33] & -0.1 & {$[.47]$} \\
\hline $\mathrm{EF} / \mathrm{A}$ & Low-Medium & -0.2 & {$[.00]$} & 0.2 & {$[.02]$} & 0.2 & {$[.00]$} & 0.1 & [.16] & 0.1 & {$[.32]$} & -0.1 & {$[.12]$} & 0.2 & {$[.01]$} & 0.2 & {$[.00]$} \\
\hline GS & Low-Medium & -0.3 & {$[.02]$} & 0.2 & {$[.03]$} & 0.3 & {$[.01]$} & 0.2 & [.14] & 0.2 & {$[.15]$} & -0.2 & [.13] & 0.3 & {$[.02]$} & 0.2 & {$[.09]$} \\
\hline
\end{tabular}


Table 7. Conditional Market Betas. Regressions of long-short portfolio returns on the market risk premium (RMRF) and the market risk premium interacted with measures of sentiment (S), each standardized to have unit variance.

$$
R_{X_{i t}=h i g h, t}-R_{X_{i t}=\text { low }, t}=c+d S E N T I M E N T_{t-1}+\beta\left(e+f S E N T I M E N T_{t-1}\right) R M R F_{t}+u_{t}
$$

The long-short portfolios are formed based on firm characteristics (X): firm size (ME), age, total risk ( $\sigma$ ), profitability (E), dividends (D), book-to-market ratio (BE/ME), external finance over assets (EF/A), and sales growth decile (GS). High is defined as a firm in the top three NYSE deciles; low is defined as a firm in the bottom three NYSE deciles; medium is defined as a firm in the middle four NYSE deciles. Monthly returns are matched to the closed-end fund discount (CEFD), the number of IPOs (NIPO), and the equity share (S) for the calendar year one year before $t$. Monthly returns are matched to detrended log turnover (TURN), the average annual first-day return (RIPO), and the dividend premium ( $\mathrm{P}^{\mathrm{D}-\mathrm{ND}}$ ) for the calendar year two years before $t$. All sentiment measures are orthogonalized to macroeconomic conditions. T-statistics are heteroskedasticity robust.

\begin{tabular}{|c|c|c|c|c|c|c|c|c|c|c|c|c|c|c|c|}
\hline & & \multicolumn{2}{|c|}{$C E F D_{t-1}$} & \multicolumn{2}{|c|}{$T_{U U R N_{t-2}}$} & \multicolumn{2}{|c|}{$N I P O_{t-1}$} & \multicolumn{2}{|c|}{$R I P O_{t-2}$} & \multicolumn{2}{|c|}{$S_{t-1}$} & \multicolumn{2}{|c|}{$P_{t-2}^{D-N D}$} & \multicolumn{2}{|c|}{ SENTIMENT $_{t-1}$} \\
\hline & & $\beta \mathbf{f}$ & $\mathbf{t}(\beta \mathbf{f})$ & $\beta \mathbf{f}$ & $\mathbf{t}(\beta \mathbf{f})$ & $\beta \mathbf{f}$ & $\mathbf{t}(\beta \mathbf{f})$ & $\beta \mathbf{f}$ & $\mathbf{t}(\beta \mathbf{f})$ & $\beta \mathbf{f}$ & $\mathbf{t}(\beta \mathbf{f})$ & $\beta \mathbf{f}$ & $\mathbf{t}(\beta \mathbf{f})$ & $\beta \mathbf{f}$ & $\mathbf{t}(\beta \mathbf{f})$ \\
\hline $\mathrm{ME}$ & SMB & -0.01 & {$[-0.2]$} & -0.02 & {$[-0.6]$} & -0.03 & {$[-0.8]$} & 0.02 & {$[0.5]$} & -0.01 & {$[-0.3]$} & 0.05 & [1.4] & -0.02 & {$[-0.5]$} \\
\hline Age & High-Low & -0.02 & {$[-0.5]$} & $-0.13^{\mathrm{b}}$ & {$[-2.9]$} & 0.01 & [0.4] & $-0.13^{b}$ & {$[-2.7]$} & 0.02 & {$[0.6]$} & $0.15^{\mathrm{b}}$ & [3.0] & $-0.10^{\mathrm{b}}$ & {$[-2.2]$} \\
\hline$\sigma$ & High-Low & 0.05 & [1.1] & 0.10 & [2.0] & -0.07 & {$[-1.7]$} & 0.10 & [1.9] & -0.06 & {$[-1.3]$} & -0.07 & {$[-1.4]$} & 0.04 & [0.8] \\
\hline $\mathrm{E}$ & $>0-<0$ & 0.08 & [1.7] & 0.09 & [1.9] & -0.06 & {$[-1.6]$} & 0.05 & [0.9] & -0.07 & {$[-1.5]$} & -0.04 & {$[-0.7]$} & 0.00 & [0.0] \\
\hline $\mathrm{D}$ & $>0-<0$ & -0.02 & {$[-0.5]$} & $-0.10^{\mathrm{b}}$ & {$[-2.2]$} & 0.05 & [1.2] & -0.08 & {$[-1.8]$} & 0.02 & {$[0.6]$} & 0.06 & [1.4] & -0.05 & {$[-1.0]$} \\
\hline $\mathrm{BE} / \mathrm{ME}$ & HML & 0.04 & [0.9] & $-0.12^{\mathrm{b}}$ & {$[-3.0]$} & -0.06 & {$[-1.7]$} & $-0.08^{\mathrm{b}}$ & {$[-2.2]$} & -0.07 & {$[-1.9]$} & $0.16^{\mathrm{a}}$ & [3.6] & $-0.12^{\mathrm{b}}$ & {$[-3.2]$} \\
\hline $\mathrm{EF} / \mathrm{A}$ & High-Low & 0.00 & {$[0.2]$} & $0.08^{\mathrm{b}}$ & [4.1] & -0.00 & {$[0.0]$} & $0.10^{\mathrm{b}}$ & {$[4.4]$} & -0.00 & {$[-0.3]$} & $-0.14^{\mathrm{b}}$ & {$[-6.8]$} & $0.09^{\mathrm{b}}$ & [3.9] \\
\hline GS & High-Low & -0.03 & {$[-0.2]$} & 0.30 & [1.3] & -0.19 & {$[-1.0]$} & $0.55^{\mathrm{b}}$ & {$[3.3]$} & 0.06 & {$[0.3]$} & $-0.84^{\mathrm{b}}$ & {$[-3.8]$} & $0.46^{\mathrm{b}}$ & [2.1] \\
\hline $\mathrm{BE} / \mathrm{ME}$ & Low-Medium & 0.01 & [0.2] & $-0.07^{\mathrm{b}}$ & {$[-2.5]$} & -0.01 & {$[-0.3]$} & $-0.09^{\mathrm{b}}$ & {$[-2.8]$} & -0.04 & {$[-1.4]$} & $0.12^{\mathrm{b}}$ & [3.4] & $-0.09^{\mathrm{b}}$ & {$[-2.8]$} \\
\hline $\mathrm{EF} / \mathrm{A}$ & High-Medium & 0.01 & [0.7] & $0.07^{\mathrm{b}}$ & [3.0] & -0.02 & {$[-1.0]$} & $0.08^{\mathrm{b}}$ & [3.2] & -0.01 & {$[-0.4]$} & $-0.09^{\mathrm{b}}$ & {$[-3.4]$} & $0.06^{\mathrm{b}}$ & [2.4] \\
\hline GS & High-Medium & -0.00 & {$[-0.2]$} & $0.07^{\mathrm{b}}$ & {$[3.0]$} & -0.01 & {$[-0.6]$} & $0.08^{\mathrm{b}}$ & [3.6] & -0.00 & {$[-0.1]$} & $-0.10^{\mathrm{b}}$ & {$[-4.1]$} & $0.07^{\mathrm{b}}$ & [2.8] \\
\hline $\mathrm{BE} / \mathrm{ME}$ & High-Medium & 0.03 & [1.9] & $-0.06^{\mathrm{a}}$ & {$[-3.3]$} & $-0.05^{\mathrm{a}}$ & {$[-2.6]$} & $-0.04^{\mathrm{a}}$ & {$[-3.2]$} & -0.03 & {$[-1.6]$} & $0.10^{\mathrm{a}}$ & [4.5] & $-0.07^{\mathrm{a}}$ & {$[-3.9]$} \\
\hline $\mathrm{EF} / \mathrm{A}$ & Low-Medium & -0.01 & {$[-0.8]$} & 0.02 & {$[1.2]$} & 0.02 & [1.3] & 0.02 & {$[1.3]$} & 0.00 & {$[0.3]$} & $-0.05^{\mathrm{a}}$ & {$[-3.5]$} & 0.03 & [1.9] \\
\hline GS & Low-Medium & 0.00 & {$[0.0]$} & -0.04 & {$[-1.7]$} & -0.01 & {$[-0.4]$} & -0.03 & {$[-1.7]$} & 0.01 & {$[0.4]$} & 0.01 & {$[0.7]$} & -0.02 & {$[-1.1]$} \\
\hline
\end{tabular}

${ }^{\text {a }}$ Statistically significant $\beta f$ that matches the sign of the return predictability from Tables 5 and 6.

${ }^{\mathrm{b}}$ Statistically significant $\beta f$ that does not match the sign of the return predictability from Tables 5 and 6 . 
Table 8. Announcement Effects. For each calendar quarter, we form ten portfolios according to the NYSE breakpoints of firm size (ME), age, total risk, earnings-book ratio for profitable firms (E/BE), dividend-book ratio for dividend payers (D/BE), book-to-market ratio (BE/ME), external finance over assets (EF/A), and sales growth (GS). We also calculate average announcement effects for unprofitable firms and nonpayers. We then regress the average quarterly earnings announcement effects for each portfolio on lagged values of the sentiment index.

$$
R_{t}=a+b S E N T I M E N T_{t-1}+u_{t}
$$

We report $b$. Quarterly average announcement effects are matched to the sentiment index for the calendar year one year before $t$. The sentiment measure is orthogonalized to macroeconomic conditions. T-statistics are heteroske dasticity robust.

\begin{tabular}{|c|c|c|c|c|c|c|c|c|c|c|c|}
\hline & \multicolumn{11}{|c|}{ Decile } \\
\hline & $\leq \mathbf{0}$ & 1 & 2 & 3 & 4 & 5 & 6 & 7 & 8 & 9 & 10 \\
\hline \multirow[t]{2}{*}{ ME } & & -0.20 & -0.02 & -0.01 & -0.11 & -0.06 & -0.06 & -0.01 & -0.04 & 0.00 & -0.06 \\
\hline & & {$[-2.24]$} & {$[-0.28]$} & {$[-0.11]$} & {$[-1.26]$} & {$[-1.02]$} & {$[-0.88]$} & {$[-0.22]$} & {$[-0.77]$} & [0.04] & [-1.09] \\
\hline \multirow[t]{2}{*}{ Age } & & -0.09 & 0.01 & -0.08 & -0.10 & -0.15 & 0.00 & 0.05 & -0.05 & -0.03 & -0.15 \\
\hline & & {$[-0.84]$} & {$[0.10]$} & {$[-1.23]$} & {$[-1.22]$} & {$[-2.01]$} & {$[-0.04]$} & [0.87] & {$[-0.74]$} & {$[-0.55]$} & {$[-3.09]$} \\
\hline \multirow[t]{2}{*}{$\sigma$} & & 0.06 & 0.03 & 0.01 & 0.04 & -0.07 & -0.04 & -0.02 & -0.02 & -0.08 & -0.31 \\
\hline & & [0.91] & {$[0.73]$} & {$[0.25]$} & [0.75] & {$[-1.29]$} & {$[-0.59]$} & {$[-0.21]$} & {$[-0.24]$} & {$[-1.03]$} & {$[-3.55]$} \\
\hline \multirow[t]{2}{*}{$\mathrm{E} / \mathrm{BE}$} & -0.33 & -0.23 & 0.06 & 0.11 & -0.16 & -0.13 & -0.06 & -0.03 & 0.00 & -0.01 & 0.10 \\
\hline & [-2.96] & {$[-2.19]$} & {$[0.83]$} & [0.84] & {$[-1.76]$} & {$[-1.52]$} & {$[-0.68]$} & {$[-0.32]$} & {$[0.04]$} & {$[-0.14]$} & [1.47] \\
\hline \multirow[t]{2}{*}{$\mathrm{D} / \mathrm{BE}$} & -0.19 & 0.00 & -0.09 & -0.04 & -0.02 & -0.06 & 0.00 & -0.07 & -0.11 & 0.03 & -0.05 \\
\hline & {$[-2.26]$} & {$[-0.02]$} & {$[-1.32]$} & {$[-0.64]$} & {$[-0.33]$} & {$[-1.01]$} & {$[-0.08]$} & {$[-1.20]$} & {$[-2.07]$} & [0.55] & {$[-0.72]$} \\
\hline \multirow[t]{2}{*}{$\mathrm{BE} / \mathrm{ME}$} & & -0.10 & 0.00 & 0.04 & -0.03 & -0.06 & 0.02 & -0.11 & 0.00 & -0.13 & -0.18 \\
\hline & & {$[-1.43]$} & {$[-0.07]$} & {$[0.54]$} & {$[-0.45]$} & {$[-0.90]$} & {$[0.30]$} & {$[-1.74]$} & {$[-0.03]$} & {$[-1.54]$} & [-1.62] \\
\hline \multirow[t]{2}{*}{$\mathrm{EF} / \mathrm{A}$} & & -0.06 & -0.06 & 0.03 & -0.08 & 0.01 & -0.07 & -0.15 & -0.03 & -0.14 & -0.06 \\
\hline & & {$[-0.57]$} & {$[-0.77]$} & {$[0.54]$} & {$[-1.23]$} & {$[0.11]$} & {$[-1.12]$} & {$[-2.65]$} & {$[-0.50]$} & {$[-2.02]$} & {$[-0.70]$} \\
\hline \multirow[t]{2}{*}{ GS } & & -0.24 & -0.05 & -0.11 & -0.03 & -0.03 & 0.02 & -0.07 & 0.00 & -0.06 & -0.06 \\
\hline & & {$[-2.36]$} & {$[-0.62]$} & [-1.39] & {$[-0.46]$} & {$[-0.55]$} & {$[0.34]$} & {$[-1.21]$} & {$[0.08]$} & {$[-0.91]$} & {$[-0.68]$} \\
\hline
\end{tabular}

